\title{
Disentangling a cryptic species complex and defining new species within the Eumerus minotaurus group (Diptera: Syrphidae), based on integrative taxonomy and Aegean palaeogeography
}

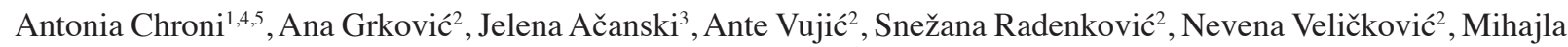 \\ Djan $^{2}$, Theodora Petanidou ${ }^{1}$ \\ ${ }^{1}$ University of the Aegean, Department of Geography, University Hill, 81100, Mytilene, Greece \\ ${ }^{2}$ University of Novi Sad, Faculty of Sciences, Department of Biology and Ecology, Trg Dositeja Obradovića 2, \\ 21000, Novi Sad, Serbia \\ ${ }^{3}$ Laboratory for Biosystems Research, BioSense Institute - Research Institute for Information Technologies in \\ Biosystems, University of Novi Sad, Dr. Zorana Đinđica 1, 21000, Novi Sad, Serbia \\ ${ }^{4}$ Institute for Genomics and Evolutionary Medicine; Department of Biology, Temple University, Philadelphia, PA \\ 19122, USA \\ ${ }^{5}$ E-mail: tonichr3@gmail.com
}

Keywords: Aegean, DNA sequences, hoverflies, midAegean Trench, wing geometric morphometry

\begin{abstract}
This study provides an overview of the Eumerus minotaurus taxon group, diagnosing a new species, E. anatolicus Grković, Vujić and Radenković sp. n. (Muğla, Turkey), and unraveling three cryptic species within E. minotaurus: E. karyates Chroni, Grković and Vujić sp. n. (Peloponnese, Greece), E. minotaurus Claussen and Lucas, 1988 (Crete and Karpathos, Greece) and E. phaeacus Chroni, Grković and Vujić sp. n. (Corfu and Mt Olympus, Greece; Mt Rumija, Montenegro). We applied an integrative taxonomic approach based on molecular, morphological and wing geometric morphometric data to corroborate and delimit cryptic species within the complex. In addition, we discuss the latent biogeographic patterns and speciation processes leading to configuration of the E. minotaurus group based on palaeogeographic evolution of the Aegean. Mitochondrial phylogeographic analysis suggested that speciation within the $E$. minotaurus group is attributable to formation of the mid-Aegean Trench and Messinian Salinity Crisis, and was integrated at the Pleistocene. We show that more accurate estimates of divergence times may be based on geological events rather than the standard arthropod mtDNA substitution rate.
\end{abstract}

\section{Contents}

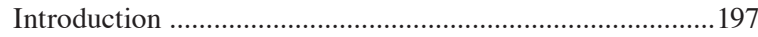

Material and methods .............................................................199

Specimen collection and morphological analysis ............199

Molecular analyses .......................................................203

Geometric morphometric analysis.................................206

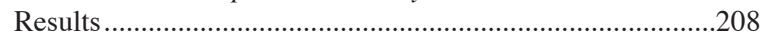

Molecular analyses ........................................................208

Geometric morphometric evidence .................................209
Discussion .......................................................................... 211

Taxonomic and molecular implications ..........................212 Mitochondrial dating, biogeographic history and divergence time estimates .................................................2213

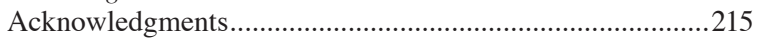

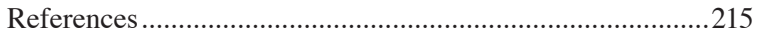

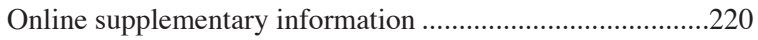

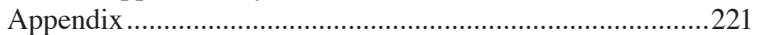

\section{Introduction}

Integrative taxonomy is a multisource approach that takes advantage of complementarity among disciplines and tends to gain ground more and more in species delimitation and diagnosis of cryptic diversity (Dayrat, 2005; Padial et al., 2010; Schlick-Steiner et al., 2010). Single-method approaches in taxonomic and systematic studies have many limitations, especially for diagnosis of cryptic species and, as a result, (two or more) distinct species are often erroneously classified (and hidden) under one species name (Bickford et al., 2007; Pfenninger and Schwenk, 2007). Cryptic species are morphologically indistinguishable but genetically distinct lineages, so a combination of molecular, biological and morphological approaches, as well as phylogeographic and population genetic analyses have been proposed (and are required) as a framework to diagnose and distinguish cryptic species (PérezPonce de León and Nadler, 2010). Mitochondrial (DNA barcodes; Hebert et al., 2003) and nuclear molecular markers (e.g. 28S, Belshaw et al., 1998) have contributed to tally up the total species diversity, leading to the prosperity of integrative taxonomy (e.g . 
hoverflies, Mengual et al., 2008) and the detection of new species (beetles, Soldati et al., 2014; butterflies, Kirichenko et al., 2015; cone snails, Puillandre et al., 2014; flies, Diaz et al., 2015) as well as cryptic species complexes (earthworms, Martinsson and Erséus, 2017; flies, Dias et al., 2016; Šašić et al., 2016; lizards, Rato et al., 2016; plants, Perez et al., 2016; rotifers, Papakostas et al., 2016).

The hoverfly genus Eumerus Meigen, 1822 (Diptera: Syrphidae) accounts of its great diversity (256 species recorded worldwide, Pape and Thompson, 2015, of which 37 occur in southeastern Europe, Grković et al.,2017), yet we know little about its fauna (unknown total species number as e.g. new species are regularly described: Doczkal, 1996; Speight et al., 2013; Grković et al., 2015, 2017; Markov et al., 2016), habitat preferences (Speight, 2016), life cycle (often strictly connected to plant species, Arzone, 1971, 1973; Pérez-Bañón and Marcos-García, 1998; Speight, 2016) or foraging behaviour (pests of vegetables, Doczkal, 1996; Pérez-Bañón and Marcos-García, 1998; flower visitors, Petanidou et al., 2011; Speight, 2016). In addition, the nomenclatural history and the taxonomic statuses within the genus are complex and unclear, highlighting the need to revise the genus' taxonomy. Considering the importance of hoverflies in ecosystems (as pollinators, predators of plant pests, herbivores, etc.; Rotheray and Gilbert, 2011), further ecological and biogeographic studies are needed; there might be more out there that we are missing which should be taken into account in, e.g. conservation outlines.

Heretofore, few studies have tackled unresolved problems of the genus Eumerus with DNA barcoding, let alone integrative taxonomy being employed. New species, some of them endemics, have been described over the past decade (Doczkal, 1996; Ricarte et al., 2012; Grković et al., 2015, 2017; Markov et al., 2016; van Steenis et al., 2017; Smit et al., 2017), and several taxon groups (hereafter named as 'groups') have been proposed within the genus (Chroni et al., 2017). The latter study suggested the configuration of the Eumerus minotaurus group with two related species: E. crassus Grković, Vujić and Radenković, 2015 (species range: Lesvos Island, Greece; originally identified as E. niehuisi Doczkal, 1996, and treated as such in the respective publication; specimen EU37) and E. minotaurus Claussen and Lucas, 1988 (species range: Crete and Thessaly, Greece; and parts of the former Yugoslavia; Speight, 2016) (Figure 1A). Doczkal (1996) discussed this topic, and suggested an affinity for E. longicornis Loew, 1855 (species range requires confirmation, but probably: southern and central Germany, Slovakia, Hungary and the Mts Caucasus; Speight, 2016), E. minotaurus, E. niehuisi (species range: Corsica and Sardinia; Doczkal, 1996) and E. sibiricus Stackelberg, 1952 (species range: Siberia; drawn by Stackelberg, 1961; Doczkal, 1996; Figure 1B). Within the frame of this study, we considered all aforementioned species (Doczkal, 1996; Chroni et al., 2017) to belong to the E. minotaurus group (Figure 1C), and we studied the species and specimens (at our disposal) originating from southeastern Europe. We have employed an integrative approach that utilizes molecular, morphological and wing morphometric data (E.crassus and E. minotaurus) or morphological data alone due to unavailability of DNA sequences (E. longicornis). Our current analyses denoted a cryptic species complex within $E$. minotaurus and one new species within the E. minotaurus group. Cryptic diversity is frequently encountered among hoverflies, with examples described for the genera Chrysotoxum (Nedeljković et al., 2013, 2015), Merodon (M. aureus group, Šašić et al., 2016; M. avidus, Popović et al., 2015, Ačanski et al., 2016; M. nanus group, Vujić et al., 2014), Microdon (M. myrmicae, Bonelli et al., 2011) and Pipiza (Vujić et al., 2013).

The Aegean archipelago and its adjacent regions (Balkan Peninsula, Greek mainland and Anatolian coast) are well-known for their high diversity of both cryptic and endemic species (Poulakakis et al., 2015), as well as for the multiple and complex alterations that have occurred from the Miocene (23 Mya) through to the Holocene (0.0117 Mya to the present) (Poulakakis et al., 2015; Gkontas et al., 2016; Kougioumoutzis et al., 2017; Sfenthourakis and Triantis, 2017). Four major geological events in the Aegean region are considered liable for significant species dispersal barriers: (1) formation of the mid-Aegean Trench (MAT) in the middle Miocene (12-9 Mya), during which a sea interference separated eastern from central-western regions (Sfenthourakis and Triantis, 2017); (2) isolation of Crete from the Peloponnese (5.5-5 Mya) after the Messinian Salinity Crisis (MSC) in the late Miocene (5.96-5.33 Mya) when the Mediterranean Sea almost desiccated allowing every species to travel anywhere wanted; (3) extensive segregation and widening of the Aegean Sea and separation of the Karpathos-Kassos island group from Rhodos in the Pliocene (5-2 Mya); and (4) orogenetic and eustatic sea-level changes during the Pleistocene (2-0.0117 Mya) (Kougioumoutzis et al., 2017; Sfenthourakis and Triantis, 2017). A series of phenomena including geological (geotectonic forces) and climatic events (sea-level oscillations) as well as 
A

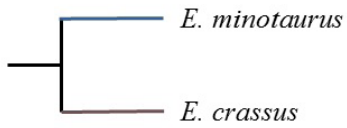

E. minotaurus group sensu Chroni et al., 2017
B

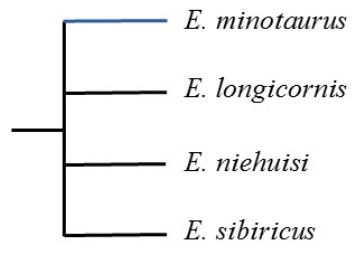

E. longicornis and related taxa sensu Doczkal, 1996

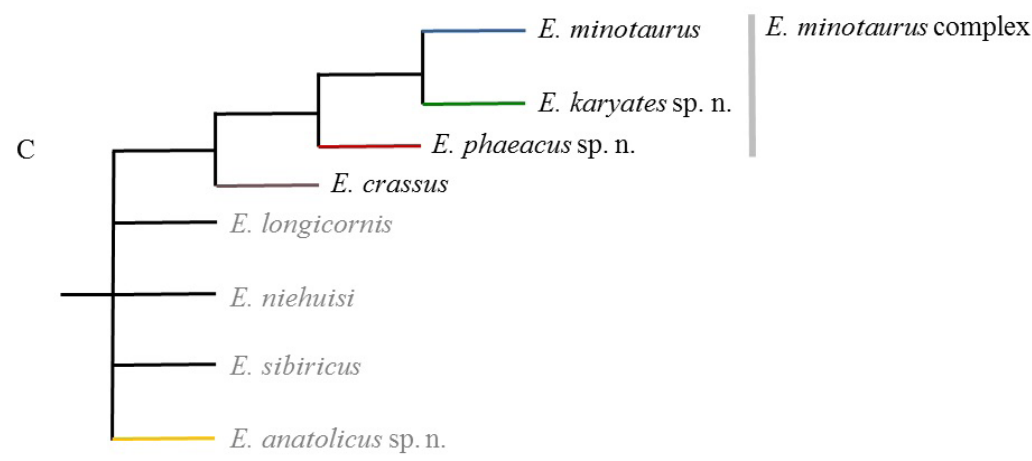

E. minotaurus group sensu Chroni et al., 2017, presented here
Figure 1. Species composition for (A) the E. minotaurus group sensu Chroni et al., 2017; (B) E. longicornis and related taxa sensu Doczkal, 1996; and (C) the E. minotaurus group sensu Chroni et al., 2017 presented here (species in grey were not included in integrative taxonomy approach due to unavailability of DNA sequences). The branches of species discussed in the present study are marked with different colours: E. anatolicus sp. n. (orange), E. crassus (grey), E. karyates sp. n. (green), E. minotaurus (blue) and $E$. phaeacus sp. n. (red) (for interpretation of the references to colour in this figure legend, the reader is asked to refer to the web version of this article). human pressure (first evidence of human settlement in the Palaeolithic, ca. 130000 years ago, Strasser et al., 2010), have shaped everything as known today, with the configuration or isolation of landmasses allowing or impeding the dispersal of organisms and thereby driving speciation or species extinction (Poulakakis et al., 2005; Parmakelis et al., 2006; Poulakakis and Sfenthourakis, 2008; Akin et al., 2010; Simaiakis et al., 2012; Gkontas et al., 2016; Sfenthourakis and Triantis, 2017).

The aims of our study were threefold: (a) to define and delimit cryptic species within E. minotaurus by integrating molecular markers (mtDNA and nDNA), subtle morphological characters and wing geometric morphometrics; (b) to provide an overview of the species within the E. minotaurus group and to explore the existence of new species within it; and (c) to investigate speciation processes and suggest a biogeographic pattern for the E. minotaurus group.

\section{Material and methods}

\section{Specimen collection and morphological analysis}

Our study relies on collections assembled by hand net between the years 2003 and 2016, and deposited in the entomological collections of the Faculty of
Sciences of Novi Sad (FSUNS), the Melissotheque of the Aegean (University of the Aegean, Mytilene, Greece, MAegean) and the Finnish Museum of Natural History (Zoological Museum, Helsinki, Finland, MZH). The specimens of E. anatolicus sp. n. were collected by Malaise trap and belong to the Miroslav Barták collection (Faculty of Agrobiology, Food and Natural Resources, Czech University of Life Sciences, Prague). A total of 52 specimens from 19 species of Eumerus, representing 33 sampling localities, were used for the molecular analyses (Figure 2; Table 1; 15 specimens of representative Eumerus species and 37 of the E. minotaurus group. Sample sizes and provenances of the studied E. minotaurus group specimens used for morphological/molecular/wing morphometry analyses were, respectively (Figure 2): E. crassus (Greece: Chios, Evros, Lesvos, Mt Rhodope, Samos, Thassos; Turkey: Mt Bozdag; 40/4/10 specimens), E. anatolicus sp. n. (Turkey: Muğla; 7/-/- specimens), E. karyates sp. n. (Greece: Peloponnese; 8/8/9 specimens), E. minotaurus (Greece: Crete, Karpathos; 11/7/10 specimens) and E. phaeacus sp. n. (Greece: Corfu, Mt Olympus; Montenegro: Mt Rumija; 24/18/22 specimens). Additional material of representative Eumerus species from four countries was used in the molecular analyses (see Appendix for details). Furthermore, we examined two paratypes of E. minotaurus from the Zoological 
Table 1. List of the specimens used for the molecular analyses, their locality information, and GenBank accession numbers. GenBank accession numbers of sequences: newly-generated (this study) are in boldface; previously-generated are in normal text; and retrieved from GenBank are in italics. FSUNS: Faculty of Sciences of Novi Sad, Serbia. MAegean: The Melissotheque of the Aegean, University of the Aegean, Mytilene, Greece. MZH: Finnish Museum of Natural History, Zoological Museum, Helsinki, Finland.

\begin{tabular}{|c|c|c|c|c|c|c|c|c|c|}
\hline $\begin{array}{l}\text { Sequence } \\
\text { ID }\end{array}$ & $\begin{array}{l}\text { Specimen } \\
\text { voucher }\end{array}$ & $\begin{array}{l}\text { 3'-end } \\
\text { fragment of } \\
\text { COI }\end{array}$ & $\begin{array}{l}\text { 5'-end } \\
\text { fragment of } \\
\text { COI }\end{array}$ & $28 \mathrm{~S}$ & Species name & Species group & $\begin{array}{l}\text { Species } \\
\text { subgroup }\end{array}$ & Sex & Field data \\
\hline EU10 & FSUNS:G1147 & KY865493 & KX083349 & none & $\begin{array}{l}\text { Eumerus alpinus } \\
\text { Rondani, } 1857\end{array}$ & E. alpinus & none & $\mathrm{F}$ & $\begin{array}{l}\text { Italy, Toscana, Mts } \\
\text { Apuane, near } \\
\text { OrtoBotanico, 44.056359, } \\
10.19884\end{array}$ \\
\hline EU132 & FSUNS:60653 & KY865499 & KX083380 & none & $\begin{array}{l}\text { Eumerus strigatus } \\
\text { (Fallen, 1817) }\end{array}$ & E. strigatus & none & M & Germany, Unknown \\
\hline EU135 & FSUNS:G3018 & KY865500 & KY865450 & none & $\begin{array}{l}\text { Eumerus tricolor } \\
\text { (Fabricius), } 1798\end{array}$ & E. tricolor & none & $\mathrm{F}$ & $\begin{array}{l}\text { Italy, Baragazza, 44.13217, } \\
11.19112,09 / 06 / 2013\end{array}$ \\
\hline EU146 & $\begin{array}{l}\text { FSUNS (loan by } \\
\text { Maegean):E078 } \\
7, \\
\text { UOTA_MEL02 } \\
6180\end{array}$ & KY865501 & KY865451 & KY865546 & $\begin{array}{l}\text { Eumerus } \\
\text { minotaurus } \\
\text { Claussen \& Lucas, } \\
1988\end{array}$ & E. minotaurus & E. minotaurus & M & $\begin{array}{l}\text { Greece, Karpathos, } \\
\text { Avlona, } 35.7689,27.1849 \text {, } \\
2-4 / 05 / 2012\end{array}$ \\
\hline EU149 & FSUNS:G3025 & KY865502 & KY865452 & none & $\begin{array}{l}\text { Eumerus crassus } \\
\text { Grković, Vujić \& } \\
\text { Radenković, } 2015\end{array}$ & E. minotaurus & none & M & $\begin{array}{l}\text { Greece, Chios, Kambia } \\
\text { Gorge, } 38.578499 \text {, } \\
25.979666,14 / 05 / 2009\end{array}$ \\
\hline EU16 & FSUNS:G0278 & KY865494 & KY865446 & KY865545 & $\begin{array}{l}\text { Eumerus phaeacus } \\
\text { Chroni, Grković \& } \\
\text { Vujić, sp. n. }\end{array}$ & E. minotaurus & E. minotaurus & M & $\begin{array}{l}\text { Greece, Mt Olympus, Ag. } \\
\text { Paraskevi, kanjon, } 39.8785 \text {, } \\
22.5863,17 / 05 / 2011\end{array}$ \\
\hline EU17 & $\begin{array}{l}\text { MAegean:UOT } \\
\text { A_MEL0746, } \\
\text { E0746 }\end{array}$ & KT221020 & KT221006 & none & $\begin{array}{l}\text { Eumerus torsicus } \\
\text { Grković et Vujić, } \\
2016\end{array}$ & torsicus & none & M & $\begin{array}{l}\text { Greece, Chios, Elinda, } \\
38.393,25.9914,9- \\
11 / 11 / 2012\end{array}$ \\
\hline EU211 & FSUNS:G0277 & KY865503 & KY865453 & KY865550 & $\begin{array}{l}\text { Eumerus phaeacus } \\
\text { Chroni, Grković \& } \\
\text { Vujić, sp. n. }\end{array}$ & E. minotaurus & E. minotaurus & $\mathrm{F}$ & $\begin{array}{l}\text { Greece, Mt Olympus, Ag. } \\
\text { Paraskevi, kanjon, } 39.8785 \text {, } \\
22.5863,17 / 05 / 2011\end{array}$ \\
\hline EU212 & FSUNS:G0269 & KY865504 & KY865454 & none & $\begin{array}{l}\text { Eumerus phaeacus } \\
\text { Chroni, Grković \& } \\
\text { Vujić, sp. n. }\end{array}$ & E. minotaurus & E. minotaurus & M & $\begin{array}{l}\text { Montenegro, Mt Rumija, } \\
\text { okosredine (deokajezeru, } \\
\text { uz put), } 42.11201 \text {, } \\
19.21739,02 / 05 / 2011\end{array}$ \\
\hline EU221 & FSUNS:G0271 & KY865505 & KY865455 & none & $\begin{array}{l}\text { Eumerus sinuatus } \\
\text { Loew, } 1855\end{array}$ & E.tricolor & none & M & $\begin{array}{l}\text { Serbia, Fruska Gora, } \\
\text { Glavica, 45.153999, } \\
19.834681,17 / 06 / 2011\end{array}$ \\
\hline EU223 & FSUNS:G1020 & KY865506 & KY865456 & none & $\begin{array}{l}\text { Eumerus armatus } \\
\text { Ricarte \& } \\
\text { Rotheray, } 2012\end{array}$ & E.tricolor & none & M & $\begin{array}{l}\text { Greece, Samos, near } \\
\text { Platanos, 37.740527, } \\
26.742116,09 / 06 / 2010\end{array}$ \\
\hline EU276 & FSUNS:08910 & KY865507 & KY272852 & none & $\begin{array}{l}\text { Eumerus } \\
\text { pannonicus } \\
\text { Ricarte, Vujić \& } \\
\text { Radenković, } 2016\end{array}$ & E.strigatus & none & $\mathrm{F}$ & $\begin{array}{l}\text { Serbia, Mokrin, } \\
\text { Pašnjacivelikedroplje, } \\
45.90615,20.3018, \\
11 / 06 / 2014\end{array}$ \\
\hline EU297 & FSUNS:06366 & KY865508 & KX083386 & none & $\begin{array}{l}\text { Eumerus } \\
\text { minotaurus } \\
\text { Claussen \& Lucas, } \\
1988\end{array}$ & E. minotaurus & E. minotaurus & $\mathrm{F}$ & $\begin{array}{l}\text { Greece, Lassithi, Iraklion, } \\
7 \mathrm{~km} \text { prePlateau of } \\
\text { Lassithi, } 35.211883 \text {, } \\
25.461649,22 / 04 / 2014\end{array}$ \\
\hline EU298 & FSUNS:06452 & KY865509 & KY865457 & none & $\begin{array}{l}\text { Eumerus } \\
\text { minotaurus } \\
\text { Claussen \& Lucas, } \\
1988\end{array}$ & E. minotaurus & E. minotaurus & M & $\begin{array}{l}\text { Greece, Chania, } 3 \mathrm{~km} \text { pre } \\
\text { Armeni, } 35.285761 \text {, } \\
24.468983,25 / 04 / 2014\end{array}$ \\
\hline EU300 & FSUNS:06557 & KY865510 & KY865458 & KY865549 & $\begin{array}{l}\text { Eumerus karyates } \\
\text { Chroni, Grković \& } \\
\text { Vujić, sp. n. }\end{array}$ & E. minotaurus & E. minotaurus & M & $\begin{array}{l}\text { Greece, Peloponnese, } \\
\text { Karyes, } 25 \mathrm{~km} \mathrm{~N} \text { from } \\
\text { Sparti, } 37.304145, \\
22.421241\end{array}$ \\
\hline EU302 & FSUNS:06710 & KY865511 & KY865459 & none & $\begin{array}{l}\text { Eumerus } \\
\text { minotaurus } \\
\text { Claussen \& Lucas, } \\
1988\end{array}$ & E. minotaurus & E. minotaurus & $\mathrm{F}$ & $\begin{array}{l}\text { Greece, Chania, Imbors, } \\
35.252332,24.174351, \\
27 / 05 / 2014\end{array}$ \\
\hline EU303 & FSUNS:06728 & KY865512 & KY865460 & KY865547 & $\begin{array}{l}\text { Eumerus } \\
\text { minotaurus } \\
\text { Claussen \& Lucas, } \\
1988\end{array}$ & E. minotaurus & E. minotaurus & M & $\begin{array}{l}\text { Greece, Chania, Omalos } \\
\text { plain, } 35.322592, \\
23.930496,28 / 05 / 2014\end{array}$ \\
\hline EU320 & FSUNS:06561 & KY865513 & KX083382 & none & $\begin{array}{l}\text { Eumerus sogdianus } \\
\text { Stackelberg, } 1952\end{array}$ & E. strigatus & none & $\mathrm{F}$ & $\begin{array}{l}\text { Greece, Peloponnese, } \\
\text { Karyes } 2,25 \mathrm{~km} \mathrm{~N} \text { from } \\
\text { Sparti, 37.30416, 22.42106 }\end{array}$ \\
\hline EU37 & FSUNS:G2286 & KY865495 & KY865447 & none & $\begin{array}{l}\text { Eumerus crassus } \\
\text { Grković, Vujić \& } \\
\text { Radenković, } 2015\end{array}$ & E. minotaurus & none & M & $\begin{array}{l}\text { Greece, Lesvos, Argennos, } \\
39.357622,26.254769,03- \\
04 / 06 / 2012\end{array}$ \\
\hline EU406 & FSUNS:E1333 & KY865514 & KY865461 & none & $\begin{array}{l}\text { Eumerus } \\
\text { sulcitibius } \\
\text { Róndani, } 1868\end{array}$ & E. sulcitibius & none & $\mathrm{F}$ & $\begin{array}{l}\text { Greece, Lassithi, Psichro, } \\
35.15,25.4666667, \\
\text { Unknown }\end{array}$ \\
\hline
\end{tabular}


Table 1 continued

\begin{tabular}{|c|c|c|c|c|c|c|c|c|c|}
\hline $\begin{array}{l}\text { Sequence } \\
\text { ID }\end{array}$ & $\begin{array}{l}\text { Specimen } \\
\text { voucher }\end{array}$ & $\begin{array}{l}\text { 3'-end } \\
\text { fragment of } \\
\text { COI }\end{array}$ & $\begin{array}{l}5 \text { '-end } \\
\text { fragment of } \\
\text { COI }\end{array}$ & $28 \mathrm{~S}$ & Species name & Species group & $\begin{array}{l}\text { Species } \\
\text { subgroup }\end{array}$ & Sex & Field data \\
\hline EU459 & FSUNS:E1260 & KY865515 & KY865462 & none & $\begin{array}{l}\text { Eumerus amoenus } \\
\text { Loew, } 1848\end{array}$ & E. strigatus & none & $\mathrm{F}$ & $\begin{array}{l}\text { Greece, Mt Taygetos, Lok } \\
\text { I, 37.066156, 22.265413, } \\
06 / 08 / 2014\end{array}$ \\
\hline EU469 & FSUNS:07982 & KY865516 & KX083351 & none & $\begin{array}{l}\text { Eumerus clavatus } \\
\text { Becker, } 1923\end{array}$ & E. clavatus & none & $\mathrm{F}$ & $\begin{array}{l}\text { Turkey, Mt Davraz, ski } \\
\text { center, } 37.781694, \\
30.75871\end{array}$ \\
\hline EU499 & FSUNS:GO290 & KY865517 & KY865463 & none & $\begin{array}{l}\text { Eumerus crassus } \\
\text { Grković, Vujić \& } \\
\text { Radenković, } 2015\end{array}$ & E. minotaurus & none & $\mathrm{F}$ & $\begin{array}{l}\text { Greece, Samos, Neochori, } \\
37.707965,26.769917, \\
\text { Unknown }\end{array}$ \\
\hline EU73 & FSUNS:G0292 & KY865496 & KX083373 & none & $\begin{array}{l}\text { Eumerus consimilis } \\
\text { Šimić \&Vujić, } \\
1996\end{array}$ & E. strigatus & none & $\mathrm{M}$ & $\begin{array}{l}\text { Serbia, Djerdap, } 44.54104 \text {, } \\
22.02024,01 / 09 / 2011\end{array}$ \\
\hline EU75 & FSUNS:G0992 & KY865497 & KY865448 & none & $\begin{array}{l}\text { Eumerus clavatus } \\
\text { Becker, } 1923\end{array}$ & E. basalis & none & M & $\begin{array}{l}\text { Greece, Ikaria, near } \\
\text { Hristos, 37.601523, } \\
26.084755,11 / 06 / 2010\end{array}$ \\
\hline EU99 & FSUNS:G2219 & KY865498 & KY865449 & none & $\begin{array}{l}\text { Eumerus ornatus } \\
\text { Meigen, } 1822\end{array}$ & E. ornatus & none & M & $\begin{array}{l}\text { Montenegro, Boka } \\
\text { Kotorska, Morinj Bay, } \\
42.490394,18.648914, \\
08 / 10 / 2010\end{array}$ \\
\hline GUN5 & FSUNS:GUN5 & KY865492 & KX083393 & KY865574 & $\begin{array}{l}\text { Megatrigon } \\
\text { tabanoides } \\
\text { Doczkal, } \\
\text { Radenković, } \\
\text { Lyneborg \& Pape, } \\
2015\end{array}$ & Outgroup & none & M & South Africa, Unknown \\
\hline Y1711E & MZH:Y1711 & KY865491 & KY865444 & $\begin{array}{l}K M 224496 \\
(G B)\end{array}$ & $\begin{array}{l}\text { Platynochaetus } \\
\text { setosus Fabricius, } \\
1794\end{array}$ & Outgroup & none & M & $\begin{array}{l}\text { France, Banyuls-sur-Mer, } \\
\text { Pyrenées-Orientales, } \\
\text { JardinMediterranéen, } \\
42.474144,3.117728\end{array}$ \\
\hline EU558 & $\begin{array}{l}\text { MAegean:UOT } \\
\text { A_MEL082471, } \\
10064\end{array}$ & KY865518 & KY865464 & none & $\begin{array}{l}\text { Eumerus } \\
\text { pulchellus Loew, } \\
1848\end{array}$ & E. pulchellus & none & M & $\begin{array}{l}\text { Greece, Anafi, } \\
\text { Helicodrome, } 36.3565, \\
25.7736,15-17 / 06 / 2013\end{array}$ \\
\hline TS240 & FSUNS:06666 & KY865520 & KY865466 & KY865552 & $\begin{array}{l}\text { Eumerus } \\
\text { minotaurus } \\
\text { Claussen \& Lucas, } \\
1988\end{array}$ & E. minotaurus & E. minotaurus & M & $\begin{array}{l}\text { Greece, Rethymnon, } \\
\text { Fotinos, 35.285762, } \\
24.468983,26 / 05 / 2014\end{array}$ \\
\hline TS241 & FSUNS: 6724 & KY865521 & KY865467 & none & $\begin{array}{l}\text { Eumerus } \\
\text { minotaurus } \\
\text { Claussen \& Lucas, } \\
1988\end{array}$ & E. minotaurus & E. minotaurus & $\mathrm{F}$ & $\begin{array}{l}\text { Greece, Chania, Omalos } \\
\text { plain, 35.322592, } \\
23.930496,28 / 05 / 2014\end{array}$ \\
\hline MN1 & FSUNS:11413 & KY865522 & KY865468 & KY865558 & $\begin{array}{l}\text { Eumerus phaeacus } \\
\text { Chroni, Grković \& } \\
\text { Vujić, sp. n. }\end{array}$ & E. minotaurus & E. minotaurus & M & $\begin{array}{l}\text { Greece, Corfu, nr Ano } \\
\text { Korakiana, 39.69882, } \\
19.786956,24 / 05 / 2016\end{array}$ \\
\hline MN2 & FSUNS:11415 & KY865523 & KY865469 & KY865572 & $\begin{array}{l}\text { Eumerus phaeacus } \\
\text { Chroni, Grković \& } \\
\text { Vujić, sp. n. }\end{array}$ & E. minotaurus & E. minotaurus & M & $\begin{array}{l}\text { Greece, Corfu, nr Ano } \\
\text { Korakiana, 39.69882, } \\
19.786956,24 / 05 / 2016\end{array}$ \\
\hline MN3 & FSUNS:11419 & KY865524 & KY865470 & KY865565 & $\begin{array}{l}\text { Eumerus phaeacus } \\
\text { Chroni, Grković \& } \\
\text { Vujić, sp. n. }\end{array}$ & E. minotaurus & E. minotaurus & M & $\begin{array}{l}\text { Greece, Corfu, nr Ano } \\
\text { Korakiana, 39.69882, } \\
19.786956,24 / 05 / 2016\end{array}$ \\
\hline MN4 & FSUNS: 11458 & KY865525 & KY865471 & KY865566 & $\begin{array}{l}\text { Eumerus phaeacus } \\
\text { Chroni, Grković \& } \\
\text { Vujić, sp. n. }\end{array}$ & E. minotaurus & E. minotaurus & M & $\begin{array}{l}\text { Greece, Corfu, nr Liapades, } \\
39.673537,19.756369, \\
24 / 05 / 2016\end{array}$ \\
\hline MN5 & FSUNS:11457 & KY865526 & KY865472 & KY865570 & $\begin{array}{l}\text { Eumerus phaeacus } \\
\text { Chroni, Grković \& } \\
\text { Vujić, sp. n. }\end{array}$ & E. minotaurus & E. minotaurus & M & $\begin{array}{l}\text { Greece, Corfu, nr Liapades, } \\
39.673537,19.756369 \text {, } \\
24 / 05 / 2016\end{array}$ \\
\hline MN6 & FSUNS:11546 & KY865527 & KY865473 & KY865569 & $\begin{array}{l}\text { Eumerus phaeacus } \\
\text { Chroni, Grković \& } \\
\text { Vujić, sp. n. }\end{array}$ & E. minotaurus & E. minotaurus & M & $\begin{array}{l}\text { Greece, Corfu, nr Strinilas, } \\
39.739862,19.837306, \\
24 / 05 / 2016\end{array}$ \\
\hline MN7 & FSUNS:11461 & KY865528 & KY865474 & KY865555 & $\begin{array}{l}\text { Eumerus phaeacus } \\
\text { Chroni, Grković \& } \\
\text { Vujić, sp. n. }\end{array}$ & E. minotaurus & E. minotaurus & $\mathrm{F}$ & $\begin{array}{l}\text { Greece, Corfu, nr Liapades, } \\
39.673537,19.756369 \text {, } \\
24 / 05 / 2016\end{array}$ \\
\hline MN8 & FSUNS:11460 & KY865529 & KY865475 & KY865548 & $\begin{array}{l}\text { Eumerus phaeacus } \\
\text { Chroni, Grković \& } \\
\text { Vujić, sp. n. }\end{array}$ & E. minotaurus & E. minotaurus & M & $\begin{array}{l}\text { Greece, Corfu, nr Liapades, } \\
39.673537,19.756369 \text {, } \\
24 / 05 / 2016\end{array}$ \\
\hline MN9 & FSUNS:11448 & KY865530 & KY865476 & KY865551 & $\begin{array}{l}\text { Eumerus phaeacus } \\
\text { Chroni, Grković \& } \\
\text { Vujić, sp. n. }\end{array}$ & E. minotaurus & E. minotaurus & M & $\begin{array}{l}\text { Greece, Corfu, nr } \\
\text { AnoKorakiana, 39.69882, } \\
19.786956,24 / 05 / 2016\end{array}$ \\
\hline MN10 & FSUNS:11430 & KY865531 & KY865477 & KY865559 & $\begin{array}{l}\text { Eumerus phaeacus } \\
\text { Chroni, Grković \& } \\
\text { Vujić, sp. n. }\end{array}$ & E. minotaurus & E. minotaurus & M & $\begin{array}{l}\text { Greece, Corfu, nr Ano } \\
\text { Korakiana, 39.69882, } \\
19.786956,24 / 05 / 2016\end{array}$ \\
\hline MN11 & FSUNS:11459 & KY865532 & KY865478 & KY865561 & $\begin{array}{l}\text { Eumerus phaeacus } \\
\text { Chroni, Grković \& } \\
\text { Vujić, sp. n. }\end{array}$ & E. minotaurus & E. minotaurus & M & $\begin{array}{l}\text { Greece, Corfu, nr Liapades, } \\
39.673537,19.756369, \\
24 / 05 / 2016\end{array}$ \\
\hline
\end{tabular}


Table 1 continued

\begin{tabular}{|c|c|c|c|c|c|c|c|c|c|}
\hline $\begin{array}{l}\text { Sequence } \\
\text { ID }\end{array}$ & $\begin{array}{l}\text { Specimen } \\
\text { voucher }\end{array}$ & $\begin{array}{l}\text { 3'-end } \\
\text { fragment of } \\
\text { COI }\end{array}$ & $\begin{array}{l}\text { 5'-end } \\
\text { fragment of } \\
\text { COI }\end{array}$ & $28 \mathrm{~S}$ & Species name & Species group & $\begin{array}{l}\text { Species } \\
\text { subgroup }\end{array}$ & Sex & Field data \\
\hline MN12 & FSUNS:11432 & KY865533 & KY865479 & KY86555 & $\begin{array}{l}\text { Eumerus phaeacus } \\
\text { Chroni, Grković \& } \\
\text { Vujić, sp. n. }\end{array}$ & E. minotaurus & E. minotaurus & M & $\begin{array}{l}\text { Greece, Corfu, nr Ano } \\
\text { Korakiana, 39.69882, } \\
19.786956,24 / 05 / 2016\end{array}$ \\
\hline MN13 & FSUNS:11436 & KY865534 & KY865480 & KY865567 & $\begin{array}{l}\text { Eumerus phaeacus } \\
\text { Chroni, Grković \& } \\
\text { Vujić, sp. n. }\end{array}$ & E. minotaurus & E. minotaurus & M & $\begin{array}{l}\text { Greece, Corfu, nr Ano } \\
\text { Korakiana, 39.69882, } \\
19.786956,24 / 05 / 2016\end{array}$ \\
\hline MN14 & FSUNS:11426 & KY865535 & KY865481 & KY865562 & $\begin{array}{l}\text { Eumerus phaeacus } \\
\text { Chroni, Grković \& } \\
\text { Vujić, sp. n. }\end{array}$ & E. minotaurus & E. minotaurus & M & $\begin{array}{l}\text { Greece, Corfu, nr Ano } \\
\text { Korakiana, 39.69882, } \\
19.786956,24 / 05 / 2016\end{array}$ \\
\hline MN15 & FSUNS:11437 & KY865536 & KY865482 & KY865560 & $\begin{array}{l}\text { Eumerus phaeacus } \\
\text { Chroni, Grković \& } \\
\text { Vujić, sp. n. }\end{array}$ & E. minotaurus & E. minotaurus & M & $\begin{array}{l}\text { Greece, Corfu, nr Ano } \\
\text { Korakiana, 39.69882, } \\
19.786956,24 / 05 / 2016\end{array}$ \\
\hline MN16 & FSUNS:11310 & KY865537 & KY865483 & KY865573 & $\begin{array}{l}\text { Eumerus crassus } \\
\text { Grković, Vujić \& } \\
\text { Radenković, } 2015\end{array}$ & E. minotaurus & none & $\mathrm{F}$ & $\begin{array}{l}\text { Greece, Lesvos, Neochori } \\
\text { I, } 39.024073,26.321613 \text {, } \\
03 / 5 / 2016\end{array}$ \\
\hline MN18 & FSUNS:11411 & KY865538 & KY865484 & KY865556 & $\begin{array}{l}\text { Eumerus karyates } \\
\text { Chroni, Grković \& } \\
\text { Vujić, sp. n. }\end{array}$ & E. minotaurus & E. minotaurus & M & $\begin{array}{l}\text { Greece, Peloponnese, } \\
\text { Karyes, } 25 \mathrm{~km} \mathrm{~N} \text { from } \\
\text { Sparti, } 37.304145, \\
22.421241\end{array}$ \\
\hline MN19 & FSUNS:11412 & KY865540 & KY865485 & KY865564 & $\begin{array}{l}\text { Eumerus karyates } \\
\text { Chroni, Grković \& } \\
\text { Vujić, sp. n. }\end{array}$ & E. minotaurus & E. minotaurus & $\mathrm{F}$ & $\begin{array}{l}\text { Greece, Peloponnese, } \\
\text { Karyes, } 25 \mathrm{~km} \mathrm{~N} \text { from } \\
\text { Sparti } 37.304145 \text {, } \\
22.421241\end{array}$ \\
\hline MN20 & FSUNS:11572 & KY865539 & KY865486 & KY865554 & $\begin{array}{l}\text { Eumerus karyates } \\
\text { Chroni, Grković \& } \\
\text { Vujić, sp. n. }\end{array}$ & E. minotaurus & E. minotaurus & $\mathrm{F}$ & $\begin{array}{l}\text { Greece, Peloponnese, } \\
\text { Karyes, } 25 \mathrm{~km} \mathrm{~N} \text { from } \\
\text { Sparti, } 37.304145, \\
22.421241\end{array}$ \\
\hline MN21 & FSUNS:11573 & KY865541 & KY865487 & KY865557 & $\begin{array}{l}\text { Eumerus karyates } \\
\text { Chroni, Grković \& } \\
\text { Vujić, sp. n. }\end{array}$ & E. minotaurus & E. minotaurus & $\mathrm{F}$ & $\begin{array}{l}\text { Greece, Peloponnese, } \\
\text { Karyes, } 25 \mathrm{~km} \text { N from } \\
\text { Sparti, } 37.304145, \\
22.421241\end{array}$ \\
\hline MN22 & FSUNS:11574 & KY865542 & KY865488 & KY865563 & $\begin{array}{l}\text { Eumerus karyates } \\
\text { Chroni, Grković \& } \\
\text { Vujić, sp. n. }\end{array}$ & E. minotaurus & E. minotaurus & $\mathrm{F}$ & $\begin{array}{l}\text { Greece, Peloponnese, } \\
\text { Karyes, } 25 \mathrm{~km} \mathrm{~N} \text { from } \\
\text { Sparti, } 37.304145, \\
22.421241\end{array}$ \\
\hline MN23 & FSUNS:11571 & KY865543 & KY865489 & KY865571 & $\begin{array}{l}\text { Eumerus karyates } \\
\text { Chroni, Grković \& } \\
\text { Vujić, sp. n. }\end{array}$ & E. minotaurus & E. minotaurus & M & $\begin{array}{l}\text { Greece, Peloponnese, } \\
\text { Karyes, 25km N from } \\
\text { Sparti, } 37.304145, \\
22.421241\end{array}$ \\
\hline MN24 & FSUNS:11410 & KY865544 & KY865490 & KY865568 & $\begin{array}{l}\text { Eumerus karyates } \\
\text { Chroni, Grković \& } \\
\text { Vujić, sp. n. }\end{array}$ & E. minotaurus & E. minotaurus & $\mathrm{F}$ & $\begin{array}{l}\text { Greece, Peloponnese, } \\
\text { Karyes, } 25 \mathrm{~km} \mathrm{~N} \mathrm{from} \\
\text { Sparti, } 37.304145, \\
22.421241\end{array}$ \\
\hline TS24 & FSUNS:08451 & $\begin{array}{l}L N 890909 \\
(G B)\end{array}$ & KY865445 & KY865575 & $\begin{array}{l}\text { Merodon } \\
\text { erivanicus } \\
\text { Paramonov, } 1925 \\
\end{array}$ & Outgroup & none & M & $\begin{array}{l}\text { Turkey, Isparta, Geledost, } \\
\text { Yesilkoy, 42.250833, } \\
32.351111,29 / 05 / 2014\end{array}$ \\
\hline
\end{tabular}

Museum of Amsterdam (The Netherlands, ZMAN) and one Austrian representative of E. longicornis (deposited in FSUNS, which possesses two labels: "longicornis det. Schiner" and "Austria Alte Sammlung"). Outgroup taxa used in the phylogenetic analyses consisted of Platynochaetus setosus Fabricius, 1794 (Accession Nos. KY865491, KY865444, KM224496), Merodon erivanicus Paramonov, 1925 (Accession Nos. LN890909, KY865445, KY865575) and Megatrigon tabanoides Johnson, 1898 (Accession Nos. KY865492, KX083393, KY865574). Two sequences used for $P$. setosus (28S) and M. tabanoides (COI) were retrieved from GenBank. More details regarding the locality information and GenBank accession numbers for the specimens employed in the molecular analyses are enlisted in the Appendix.
Morphological characters used in the descriptions and drawings are based on the terminology established by Thompson (1999), and those related to male genitalia follow Doczkal (1996) and Hurkmans (1993). Colour characters are described from drymounted specimens. Male genitalia were extracted from specimens using standard methods described in Grković et al. (2015). Figures and drawings were generated from photographs of characters taken with a Leica DFC 320 (Wetzlar, Germany) camera attached to a Leica MZ16 binocular stereomicroscope and then processed in Adobe Photoshop CS3 v10.0 (Adobe Systems, San Jose, CA, USA). An ocular micrometer attached to a stereomicroscope was used for measurements. All measurements for a given view were conducted in the same plane. The width of the 
face and head were measured in line with the lower margin of the antennal sockets, in frontal view. The proportions of the antennal segments were measured from the outside. We defined the width of the vertex as the distance between the eyes at the posterior margins of the posterior ocelli. The length of the frons was measured from the eyes to the upper margin of the antennal socket. The widths of tergites 3 and 4 were measured in line with their anterior margin and the width of the abdomen across widest part. The lengths of the tergites and abdomen were measured along a median line. Abbreviations used in descriptions are: $\mathrm{T}$ - tergite, $\mathrm{S}$ - sternite, IL - interior accessory lobe of posterior surstyle lobe.

\section{Molecular analyses}

DNA amplification and sequencing

Genomic DNA extractions were performed on two to three legs from each specimen, based on the protocol of Chen et al. (2010) with slight modifications as described in Grković et al. (2015). We amplified (a) 3' and 5' fragments of mitochondrial gene Cytochrome c oxidase subunit I (COI), and (b) nuclear gene $28 \mathrm{~S}$ ribosomal DNA (28S D2 rDNA: covering the D2 variable region, also referred to as the second expansion region or second divergent domain). The $28 \mathrm{~S}$ marker was amplified for 29 out of the 52 specimens. The primers used for the PCR amplification and sequencing are listed in Table 2. PCR amplifications and purification of the PCR products were performed as described in Grković et al. (2015). DNA sequencing was conducted based on the Sanger method on an ABI 3730 DNA analyzer (Applied Biosystems, USA) at the Sequencing Service laboratory of the Finnish Institute for Molecular Medicine (http:// www.fimm.fi) and by Macrogen Inc. (The Netherlands; http://www.macrogen.com/eng/).

\section{Sequence analysis}

Raw sequences were examined and proofread in BioEdit v7.2.5 (Hall, 1999). Multiple sequence alignments were implemented in MAFFT v7 by

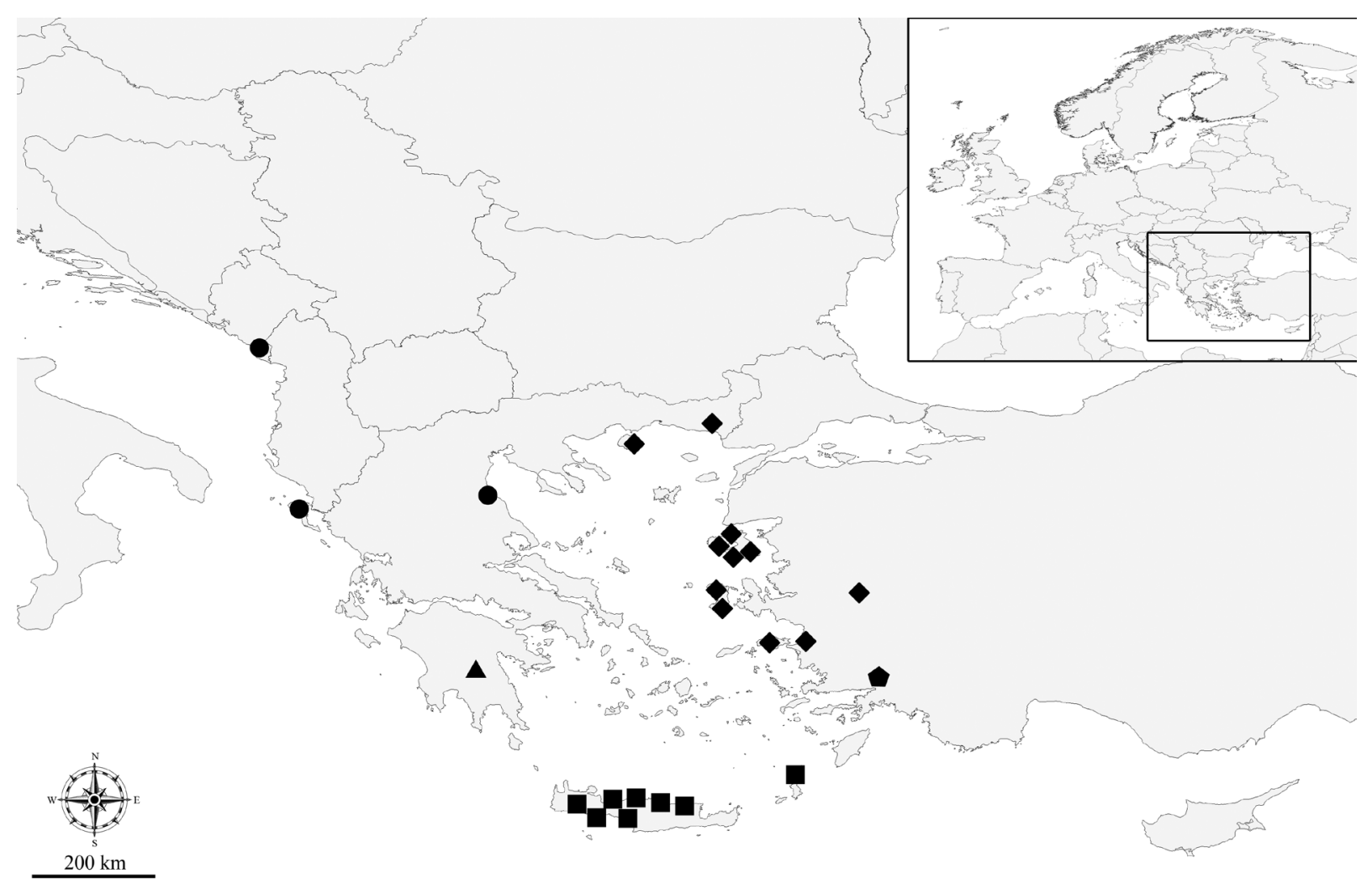

Figure 2. Distributions of all specimens used for the morphological, molecular and wing morphometric analyses.

E. minotaurus,

$\Delta$ E. karyates sp.n., E. phaeacus sp. n., E. crassus, E. anatolicus sp. n. 
Table 2. Primers used for amplification and sequencing of the mtDNA and nDNA gene fragments.

\begin{tabular}{lllr}
\hline & Primer pair & Primer sequence & Source \\
\hline 3' fragment of COI & C1-J-2183 (alias Jerry) & 5'-CAACATTTATTTTGATTTTTTGG-3' & Simon et al., 1994 \\
& TL2-N-3014 (alias Pat) & 5'-TCCAATGCACTAATCTGCCATATTA-3' & Simon et al., 1994 \\
5' fragment of COI & LCO-1490 & 5'-GGTCAACAAATCATAAAGATATTG-3' & Folmer et al., 1994 \\
& HCO-2198 & 5'-TAAACTTCAGGGTGACCAAAAAATCA-3' & Folmer et al., 1994 \\
& 28S (F2) & 5'-AGAGAGAGTTCAAGAGTACGTG-3' & Belshaw et al., 1998 \\
& 28S (3DR) & 5'-TAGTTCACCATCTITCGGGTC-3' & Belshaw et al., 1998 \\
\hline
\end{tabular}

employing the L-INS-i algorithm (see supplementary information, Data S1, S2; Katoh et al., 2005; available at http://mafft.cbrc.jp/alignment/server/index.html). Polymorphic sites, parsimony informative sites and number of haplotypes were calculated using DnaSP v5.10.01 (Librado and Rozas, 2009).

Phylogenetic analyses and tree-based species delimitation

We constructed three datasets to elucidate and corroborate the phylogenetic positions of four species within the E. minotaurus group (E. anatolicus sp. n. was excluded due to unavailability of DNA sequences) : (1) COI dataset, based on a concatenation of the 3' and 5' fragments of the COI gene (19 Eumerus taxa, $1238 \mathrm{bp}$ ); (2) $28 \mathrm{~S}$ dataset, based on the $28 \mathrm{~S}$ nuclear gene fragment (4 Eumerus taxa, 510 bp); and (3) COI subset, based on a concatenation of the 3 ' and 5' fragments of the COI gene for the E. minotaurus group alone (4 Eumerus taxa, 1238 bp) (for more details, see Table3). Representatives of other species of Eumerus (15 species) were only considered for the COI dataset in order to properly display phylogenetic positions and relationships of the species encompassing the E. minotaurus group. The phylogenetic positions and species delimitation of these 15 species were previously confirmed and discussed in Chroni et al. (2017) and Grković et al. (2017), thus we argue that the singletons used here do not jeopardize our phylogenetic inferences. The distinct morphologies of these 15 species were also accounted in species delimitation, and confirmed by the taxonomists Ante Vujić and Ana Grković.

We have inferred various phylogenetic analyses for the COI dataset as to clarify and corroborate the species topology: Maximum parsimony (MP), Maximum likelihood (ML), Neighbour joining $(\mathrm{NJ})$, Bayesian inference (BI) and split network analyses. MP analyses were performed in NONA (Goloboff, 1999), spawned in WINCLADA v1.00.08 (Nixon, 2002). A heuristics search algorithm with 1000 random addition replicates (mult x 1000) was performed with holding of 100 trees per round (hold / 100), max trees set to 100000 , and applying TBR branch swapping. The ML analysis was executed in RAxML v8.0.9 (Stamatakis, 2006; Stamatakis et $a l ., 2008$ ) in the Cipres Science Gateway (Miller et al., 2010) with 1000 bootstrap replicates. The ML analysis was implemented under the general timereversible (GTR) evolutionary model with a gamma distribution (GTR+G; Rodriguez et al., 1990) since it is the most accurate substitution model for datasets of approximately 50 taxa. We sought the best-fit substitution model for the COI dataset in MEGA v6.06 (Tamura et al., 2013), resulting in identification of the $\mathrm{GTR}+\mathrm{G}+\mathrm{I}$ model, as proposed by the Bayesian Information Criterion (BIC). We employed MEGA v6.06 (Tamura et al., 2013) to perform NJ analyses, but used the Tamura-Nei (TN93) nucleotide substitution model with a Gamma distribution (i.e. the second-best nucleotide substitution model proposed by BIC) since GTR model is not allowable in MEGA for NJ trees, and using 1000 bootstrap replicates. We assessed BI tree in MrBayes v3.2.6 (Huelsenbeck and Ronquist, 2001) in the Cipres Science Gateway (Miller et al., 2010) under the GTR+G+I model, as proposed by the BIC (Rodriguez et al., 1990). We partitioned our sequence data by codon (two partitions; positions $1 \mathrm{st}+2 \mathrm{nd}$; 3rd), which as it is recommended for protein-encoding genes as the third codon position is considered to be susceptible to higher mutational rates 
(Shapiro et al., 2006; Simmons et al., 2006; Bofkin and Goldman, 2007). The settings for the Bayesian Markov chain Monte Carlo (MCMC) process included two runs of $10 * 10 \mathrm{e}^{-6} \mathrm{MCMC}$ generations ( $\times 4$ chains) with a sampling frequency of 1000 generations and a relative burn-in of $10 \%$. MCMC results were checked with TRACER v1.6 (http://tree.bio.ed.ac.uk/ software/tracer/; Rambaut et al., 2014) and the tree was displayed in FigTree v1.4.2 (http://tree.bio.ed.ac. uk/software/figtree/; Rambaut, 2013). ML, NJ and BI trees were merged into a split network in order to extract a united tree topology. The split network was produced in SplitsTree4 v4.14.3 (Huson and Bryant, 2006) (http://www.splitstree.org/) under the parameters SuperTree, Z-closure super-network from partial trees, and heuristic analysis (number of runs: 1000). Regarding the $28 \mathrm{~S}$ dataset, we employed MP analysis, as described above. All phylogenetic trees were rooted on P. setosus.

In addition, Poisson tree processes (PTP) models were implemented in order to highlight putative molecular species clusters (Zhang et al., 2013) based on the best ML tree resulting from the RA $\times$ ML analysis of the COI dataset. PTP analyses were conducted on the web server for PTP (available at http://species.hits.org/ptp/).

Non-tree-based species delimitation

As to compare and confirm the indication of the E. minotaurus complex, non-tree-based species delimitation approaches were performed as well. Average pairwise Kimura 2-parameter (K2P) distances between the taxa of the COI dataset, and overall sequence divergence (under the $\mathrm{TN} 93+\mathrm{G}+\mathrm{I}$ model for the COI dataset and the COI subset, and under the Tamura 3-parameter for the 28S dataset; Tamura et al., 2013) were estimated in MEGA v6.06 (Tamura et al., 2013) and proposed by BIC. We have considered a threshold of $2 \%$ sequence divergence (the barcode gap) for species delimitation (outgroups were excluded; Ratnasingham and Hebert, 2013).

Network approaches can be more effective than classical phylogenetic ones for representing intraspecific evolution (Posada and Crandall, 2001), so we assessed genealogical relationships between haplotypes of the COI subset with haplotype networks constructed using the statistical parsimony algorithm implemented in the program TCS v1.21 (Clement et al., 2000) under the $95 \%$ connection limit of parsimony (gaps treated as missing data).
Molecular divergence time estimates

We created the COI subset to estimate a time-calibrated species tree, and to reconstruct the biogeographic history of species encompassing the E. minotaurus group, i.e.E.crassus, E. karyates sp. n., E. minotaurus and E. phaeacus sp. n.

Initially, we explored temporal structure in the COI subset -necessary prerequisite for reliable estimation of substitution rates- by performing a regression of root-to-tip genetic distances in TempEst (Rambaut et $a l ., 2016$ ). We used the NJ tree (generated for the COI subset as described above) as the input file.

Subsequently, we estimated divergence times using BEAST v1.8.4 (Drummond et al., 2012). The input file (.xml) was created using BEAUti v1.8.4, and we integrated the BEAGLE library (Ayres et al., 2012) into BEAST runs to achieve high-performance computing. Applied prior specifications were as follows: Relaxed Uncorrelated Lognormal Clock; Birth Death process of speciation; TN93 model with G rate heterogeneity. We also partitioned the dataset by codon (two partitions: positions 1st+2nd; 3rd, Shapiro et al., 2006; Simmons et al., 2006; Bofkin and Goldman, 2007). We have considered three approaches to calibrate the molecular clock, with employment of: (a) one calibration point based on the MAT event that separated the Aegean archipelago into its western and eastern parts (10.5 \pm 1.5 My, MAT analysis, Papadopoulou et al., 2010); (b) two calibration points where the root height was based on the MAT event and the prior of the taxon subset $E$. karyates sp. n./E. minotaurus was based on the end of the MSC event that represents permanent isolation of Crete from the Greek mainland $(5.3 \pm 0.3 \mathrm{My}$, MAT\&MSC analysis, Kasapidis et al., 2005; Kamilari et al.,2014); and (c) 2.3\% pairwise evolutionary rate per million years (My), representing the standard arthropod substitution rate for mtDNA (mtDNA-rate analysis, Brower, 1994). We also created: (i) four taxon subsets based on estimates for each of the four species within the E. minotaurus group for the MAT and mtDNA-rate analyses; and (ii) two taxon subsets, one with E. crassus sequences and one with sequences of E. karyates sp. $\mathrm{n} . /$ E. minotaurus for the MAT\&MSC analysis in order to $\log$ the time to the most common ancestor tMRCA for each taxon subset and to set the prior distributions for corresponding divergence times. Three independent runs were performed with a chain length of $10 * 10 \mathrm{e}^{-6}$ iterations for the MAT and MAT\&MSC analyses and $5^{*} 10 \mathrm{e}^{-6}$ iterations for the mtDNA-rate analysis, sampled every 1000 generations. The program TRACER v1.6 
(http://tree.bio.ed.ac.uk/software/tracer/; Rambaut et al., 2014) was employed to confirm stationarity. Independent runs were combined using Logcombiner v1.8.4 (in BEAST). The final tree with divergence time estimates was summarized with TreeAnnotator v1.8.4 (in BEAST; $10 \%$ of trees were discarded as burn-in; Maximum clade credibility tree; and Mean heights) and visualized with FigTree v1.4.2 (http://tree.bio.ed.ac.uk/software/figtree/; Rambaut, 2013).

\section{Biogeographic analyses}

To reconstruct the biogeographic history and to predict biogeographic ancestral ranges of the E. minotaurus group (COI subset), we conducted the statistical approach of Bayesian Binary MCMC (BBM) Method For Ancestral State (Ronquist and Huelsenbeck, 2003), conducted in RASP v3.2 (Yu et al., 2015). The MCMC chains were run by default, and the annotated trees from the BEAST analyses were used as input tree files. Four geographical areas were defined based on the clustering and distribution of the E. minotaurus group lineages as well as on (recorded) plant distributions (Brummitt et al., 2001; Strid, 2016): (A) Crete and Karpathos, (B) Peloponnese, (C) Balkan Peninsula, and (D) East Aegean islands (Appendix). Ancestral ranges were assumed to include from one to four areas.

\section{Geometric morphometric analysis}

Geometric morphometric analysis of wing shape was conducted on 51 specimens of the E. minotaurus group (see supplementary information $\mathrm{S} 1$ ). The right wing of each specimen was removed by means of a micro-scissors and was then mounted in Hoyer's medium on a microscopic slide. Wings have been archived and labelled with a unique code in the FSUNS collection, together with other data relevant to the specimens. High-resolution photographs of the wings were made using a Leica DFC320 video camera attached to a Leica MZ16 stereomicroscope. Ten homologous landmarks at vein intersections or terminations (that could be reliably identified) were selected using TpsDig v2.05 (Rohlf, 2006). Each wing was digitized three times to estimate the measurement error, and average landmark coordinates for each individual were used in analyses (Arnqvist and Mårtensson, 1998). All geometric morphometric analyses were conducted on a dataset in which both sexes were pooled and the male dataset separately, with allometry corrected for both datasets.

Generalised least squares Procrustes superimposition was performed in MorphoJ v2.0 (Klingenberg, 2011) on the raw coordinates to minimize nonshape variations in location, scale and orientation of

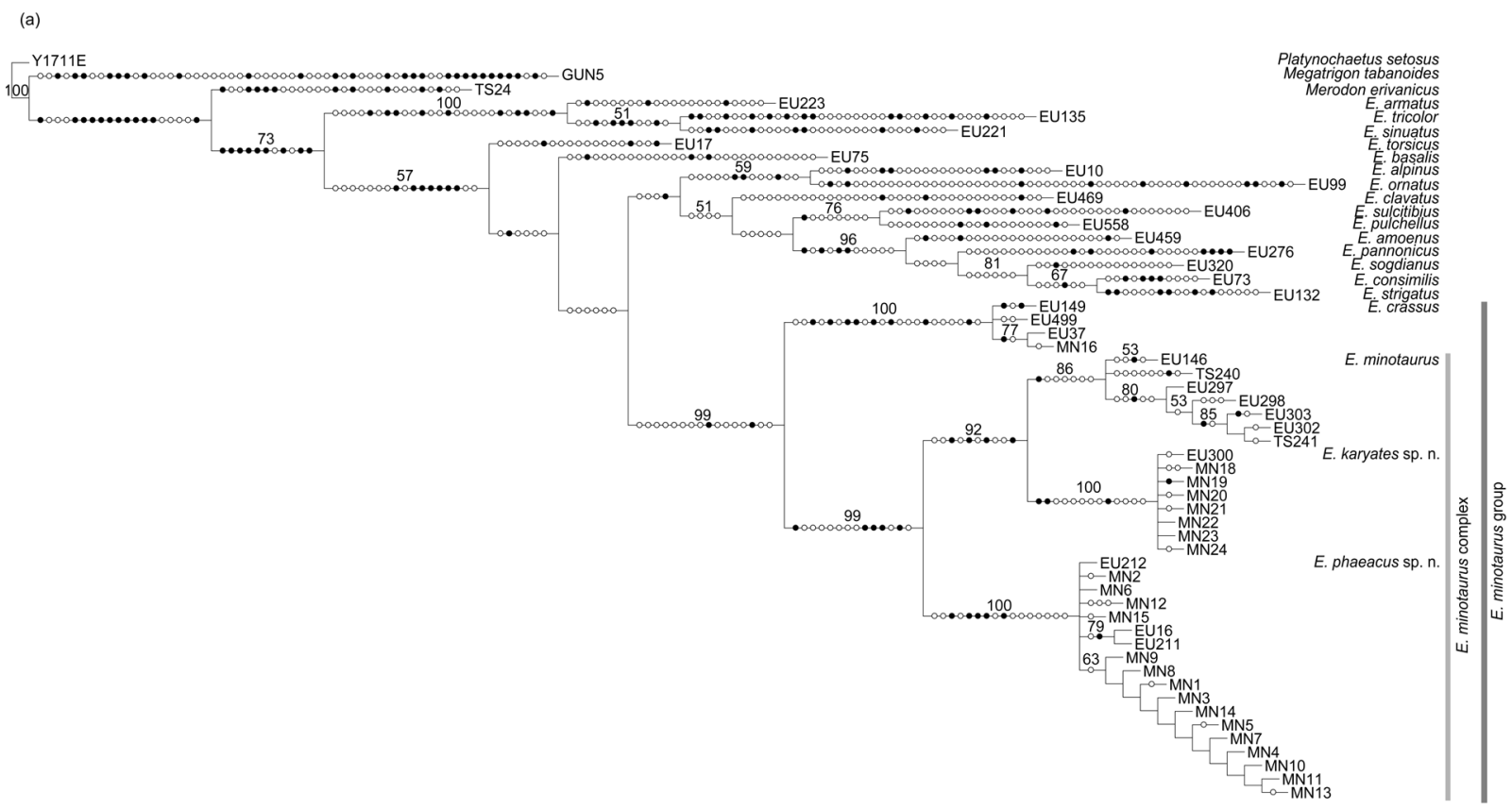

Figure 3. Maximum parsimony analyses for the concatenated 3' and 5' fragments of the COI gene (COI dataset). Only the condensed tree is illustrated here. Filled circles denote unique changes and open circles non-unique changes. Bootstrap support values are illustrated above the branches: 60 trees, Length 1122 steps, CI=44, RI=72. 


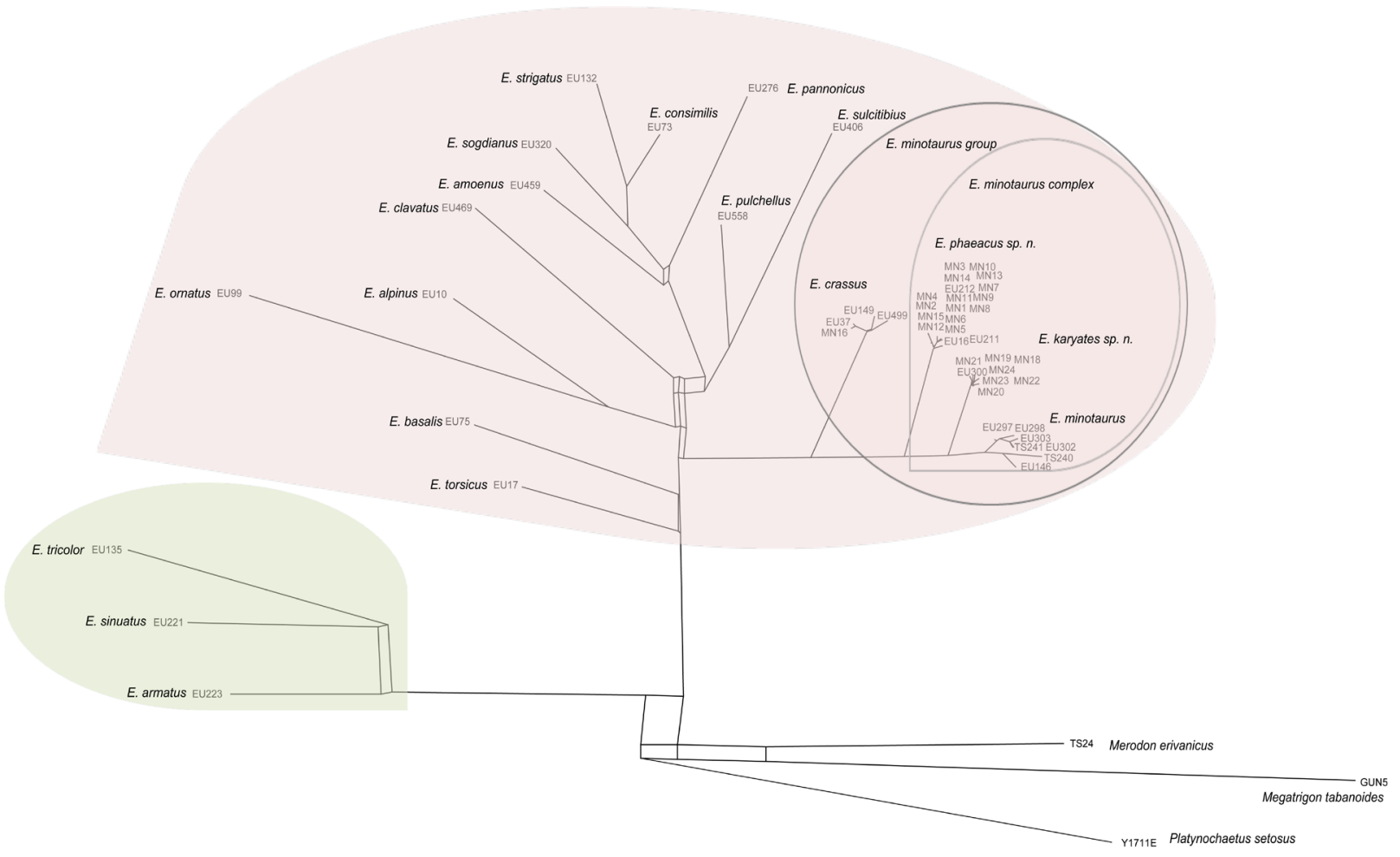

Figure 4. A phylogenetic network of ML, NJ and BI tree results for the concatenated 3' and 5' fragments of the COI gene (COI dataset).

wings, and to superimpose the wings in a common coordinate system (Rohlf and Slice, 1990; Zelditch et al., 2004). Principal component analysis was carried out on the Procrustes shape variables to reduce the dimensionality of the data set. All further statistical analyses were conducted in the reduced space using a subset of independent principal components (PCs) that describe the highest overall classification percentage calculated in stepwise discriminant analysis (Baylaac and Frieß, 2005).

To explore wing shape variation among the taxa, we employed canonical variate (CVA) and discriminant function analysis. Additionally, a Gaussian naïve Bayes classifier was used to delimit species boundaries based on wing shape variation without $a$ priori-defined groups. Phenetic relationships among taxa were determined by UPGMA analysis based on squared Mahalanobis distances computed from the discriminant function analysis applied to wing shape variables. Superimposed outline drawings produced in MorphoJ v2.0 (Klingenberg, 2011) were used to visualize differences in mean wing shape among species pairs. All statistical analyses were performed in Statistica for Windows (Dell Statistica, 2015).
Correlation among wing shape, genetic, spatial and climatic differentiation

To test correlations between morphometric, genetic, geographic and climatic distances among species, we performed Mantel tests (Mantel, 1967) with 10000 permutations in PaSSaGe (Rosenberg and Anderson, 2011). Morphometric distances were represented as a matrix of pairwise squared Mahalanobis distances, and genetic distances as a matrix of uncorrected $p$ distances (as calculated in MEGA v6.06; Tamura et al., 2013). Geographic distances were calculated as the minimum distance between two species using QGIS (Quantum GIS Development Team, 2012). Climatic distances were represented as Euclidean distances of the factor scores calculated based on 19 bioclimatic variables generated for each locality from the current climate WorldClim dataset (2.5 arc-minutes resolution) (Hijmans et al., 2005).

Two-tailed Mantel tests were performed to test pairwise correlations among the four distance matrices, and partial Mantel tests were used to explore relationships between: (i) wing shape and genetic differentiation, while accounting for the 
Table 3. Characteristics for each analyzed dataset; in the 'Sequences no' the number of outgroups is not considered.

\begin{tabular}{llll}
\hline Dataset & COI & 28S & subset COI \\
\hline Gene fragment(s) & 3' and 5' fragment of COI & 28s D2 rDNA & 3' and 5' fragment of COI \\
Taxa no & 19 & 4 & 4 \\
Sequences no & 52 & 29 & 37 \\
Sequence length (bp) & 1238 & 510 & 1238 \\
Singleton variable sites & 86 & 11 & 18 \\
Parsimony informative sites & 258 & 2 & 100 \\
Sequence divergence (\%) & 6.1 & 0.3 & 2.8 \\
Haplotypes no (with gaps/missing data: not considered) & 41 & 3 & 26 \\
Geographical clusters no (BBM analysis) & - & - & 4 \\
\hline
\end{tabular}

effect of geographic distances and climatic distances separately; and (ii) wing shape and geographic distances accounting for the genetic distances.

\section{Results}

\section{Molecular analyses}

Phylogenetic analyses: tree-based and non-tree-based species delimitation

All tree-based (MP, ML, NJ, BI, split network and PTP models, high bootstrap and probability support values; Figures 3, S2, S3, S4 and 4, respectively) and nontree-based (K2P, TCS) species delimitation analyses of the COI dataset (1238 bp) indicated four, wellsupported, clusters-species within the E. minotaurus group as well as three species within E. minotaurus, revealing the $E$. minotaurus complex. The PTP analysis returned an estimation of 22 to 26 lineages, with four within the E. minotaurus group. Interspecific genetic distances (K2P) for the COI dataset were found to be 0.025-0.117 (except for specimen TS241, $0.014)$. Sequence divergence was calculated for both the COI and 28S datasets, as well for the COI subset (Table 3). TCS analysis for the COI subset led to four independent networks, one for each species within the E. minotaurus group (S5).

Unlike the mitochondrial marker (COI dataset; S6), the nuclear molecular marker (28S dataset) could not distinguish evolutionary lineages. Moreover, the low sample size (4 species, 29 sequences) and the short sequence length (510 bp) meant we considered it of no benefit to further analyze the $28 \mathrm{~S}$ dataset. Therefore, only the results of the COI dataset were sought to be used for the species delimitation within the E.minotaurus group. Molecular divergence time estimates and biogeographic analyses

Our root-to-tip regression revealed relatively strong temporal structure in the COI subset, with a correlation coefficient of 0.1586 ( $\mathrm{R}$ squared $=0.02514$ ), allowing us to implement a molecular clock model. This analysis also indicated that the sequences EU37, EU149 ( $E$. crassus) and TS240 (E. minotaurus) are less divergent than the rest, whereas the EU297 (E. minotaurus) is the most divergent. The indication of few more or less divergent sequences was not considered as the quality of those sequences was checked and confirmed.

The time-calibrated species tree and the results of the BBM analysis are both depicted in Figure 5. Due to the similar probability values and for simplicity, we only present in Figure 5 the BBM results based on the annotated tree produced from the MAT analysis. The species-tree topology is congruent with that inferred from the phylogenetic analyses. Divergence time estimates, as assessed for the MAT and MAT\&MSC approaches are well-nigh consistent. According to the inferred dates, diversification of the E. minotaurus group dates back to the Miocene, whereas speciation within the E. minotaurus complex approximately dates to the MSC (Figure 5). The pairwise substitution rates obtained were $0.882 \%$ and $0.706 \%$ for the MAT and MAT\&MSC analyses, respectively. Divergence times for the mtDNA-rate analysis were much lower, placing the diversification of the E. minotaurus group and the E. minotaurus complex to the Pliocene and Pleistocene, respectively. All posterior probability values per lineage exceeded 0.95 (and ranged up to 1). The substitution rates were approximately 0.80 based on codon positions $1+2$, and 1.36 for codon position 3 . 
The BBM analyses from all annotated trees were congruent and suggested a total of six dispersal and three vicariant events shaped the current distribution of the E. minotaurus group, and that speciation events have occurred within areas as follow: A:6, B:7, C:17 and D:3. Dispersal events may have occurred between areas: A to B (Crete and Karpathos to Peloponnese), C to A (Balkan Peninsula to Crete and Karpathos) and $\mathrm{D}$ to $\mathrm{C}$ (East Aegean Islands to Balkan Peninsula). Three possible dispersal routes are proposed for each node; I: $\mathrm{A} \rightarrow \mathrm{BA} \rightarrow \mathrm{B} \rightarrow \mathrm{A}$, II: $\mathrm{C} \rightarrow \mathrm{CA} \rightarrow \mathrm{C} \rightarrow \mathrm{A}$ or III: $\mathrm{D} \rightarrow \mathrm{CD} \rightarrow \mathrm{C} \rightarrow \mathrm{D}$ (Figure 5).

\section{Geometric morphometric evidence}

Geometric morphometric analyses of wing shape showed the same pattern for pooled sexes and for the males separately, so only results based on the pooled dataset are presented here. Measurement (digitizing) error was negligible.

Principal component analysis carried out on the Procrustes shape variables produced 16 PCs (S7).
Stepwise discriminant analysis revealed that the first 13 PCs represented the highest overall classification percentage of investigated taxa. Canonical variates analysis conducted on these 13 PCs produced three highly significant axes (CV1: Wilks' Lambda $=0.0165$; $\chi 2=170.219 ; \mathrm{p}<0.01 ;$ CV2: Wilks' Lambda $=0.1420$; $\chi 2=80.992 ; \mathrm{p}<0.01 ;$ CV3: Wilks' Lambda $=0.4413$; $\left.\chi^{2}=33.949 ; \mathrm{p}<0.01\right)$. CV1 clearly separated $E$. crassus from $E$. phaeacus sp. n., though E. minotaurus and E. karyates sp. n. is related with CV2 and CV3. $\mathrm{CV} 2$ separated E. minotaurus from other under study species, while CV3 showed that E. karyates sp. n. differs from E. crassus, E. phaeacus sp. n. and $E$. minotaurus (Figure 6). Moreover, our discriminant function analysis showed that all species pairs differed highly significantly in wing shape $(\mathrm{p}<0.01)$ (S8). Importantly, $96 \%$ of specimens were correctly classified into a priori-defined groups, demonstrating that wing shape is a reliable character for interspecific discrimination. All specimens belonging to E. crassus and $E$. phaeacus sp. n. were correctly classified. One specimen of E. minotaurus and one of E. karyates

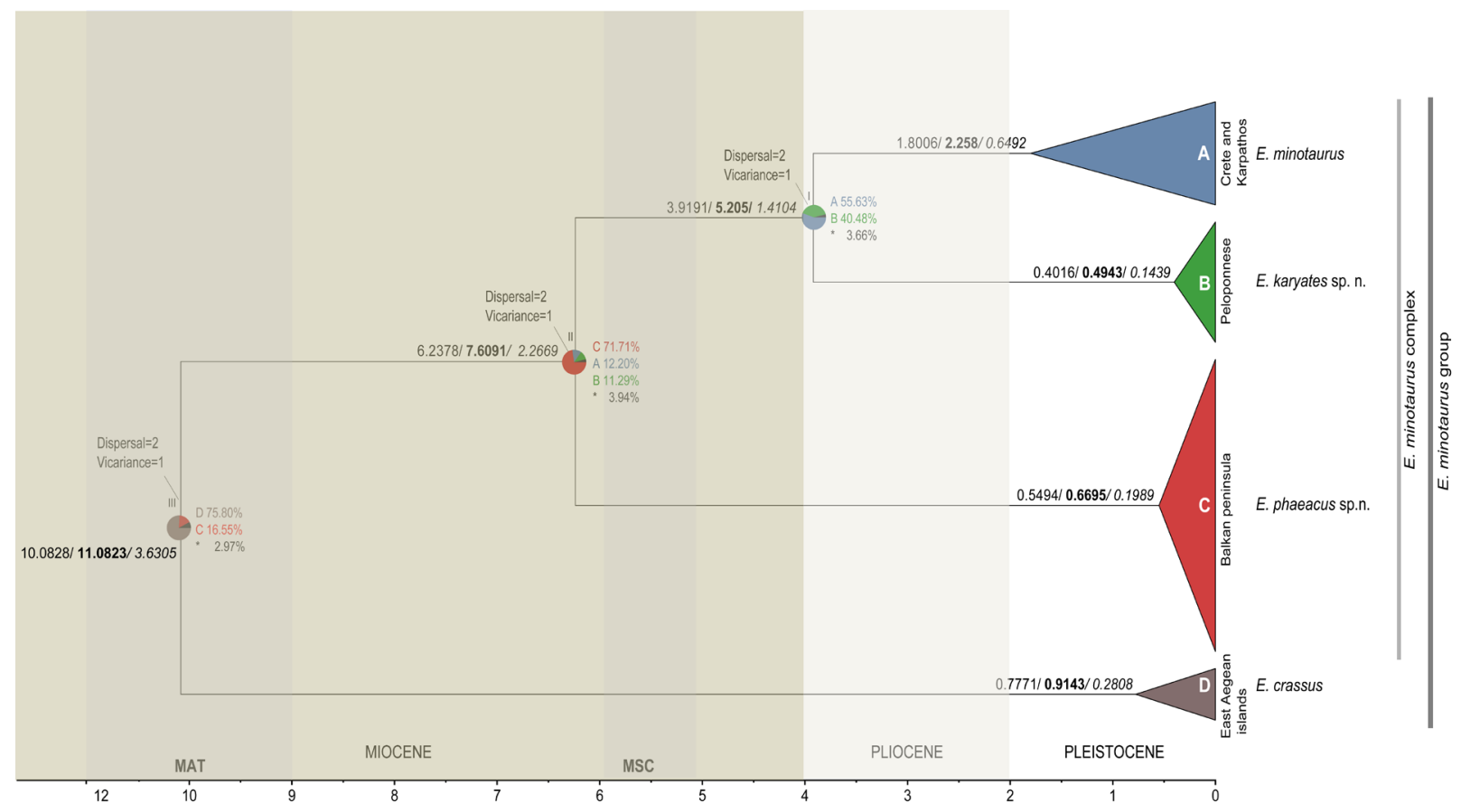

Figure 5. Trees inferred with BEAST for the concatenated 3' and 5' fragments of the COI gene (COI subset) for the E. minotaurus group. Values on the left and above the branches are mean ages estimated according to the uncorrelated log-normal clock based on (a) MAT (in normal text), (b) MAT\&MSC (in bold), and (c) 2.3\% mtDNA-rate (in italics), in Mya (a/b/c). The four defined areas are presented with different colours, percentage values (on the right side of the nodes of the tree) and pie charts at nodes I, II and III; (A) Crete and Karpathos (blue), (B) Peloponnese (green), (C) Balkan Peninsula (red), (D) East Aegean Islands (grey), and (*) unknown (black) (for interpretation of the references to colour in this figure legend, the reader is asked to refer to the web version of this article). 

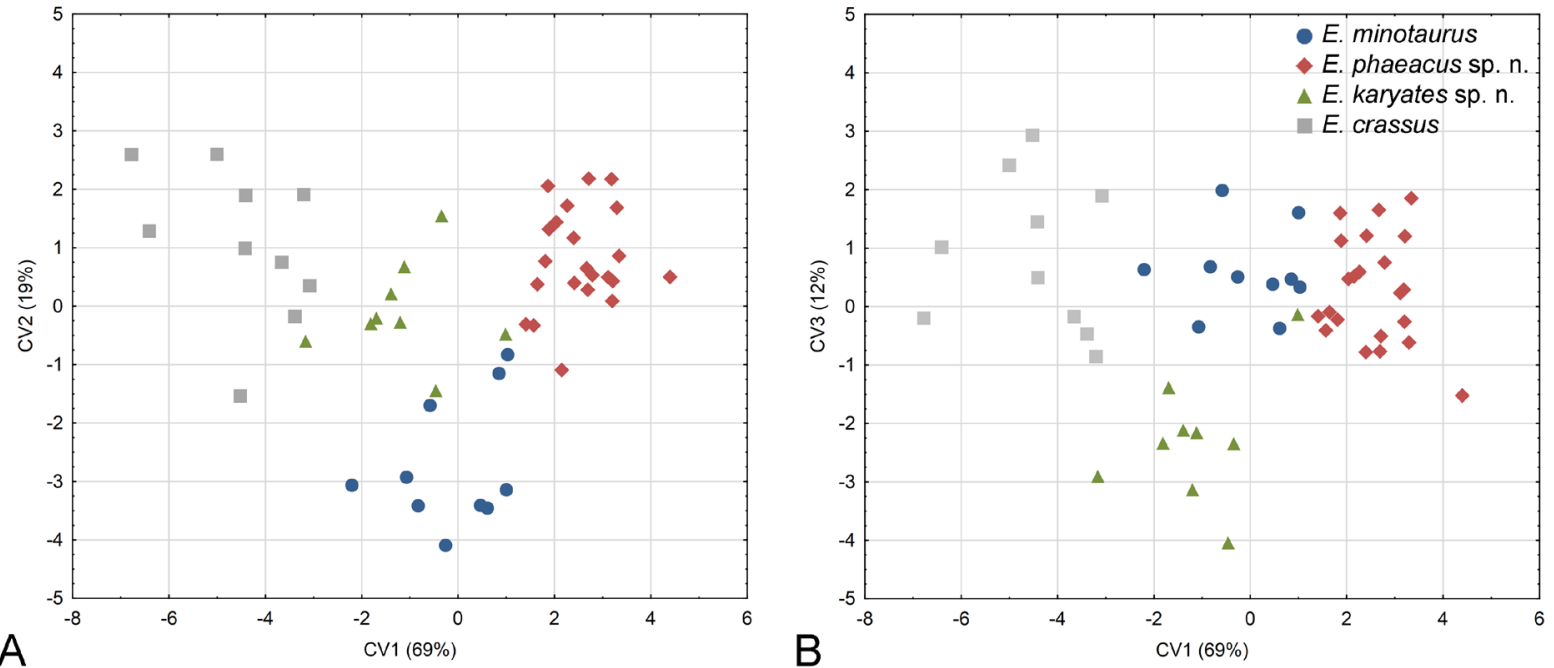

Figure 6. Shape variability among species of the Eumerus minotaurus species group: A) Scatter plot of individual scores of CV1 and CV2; and B) scatter plot of individual scores of CV1 and CV3.

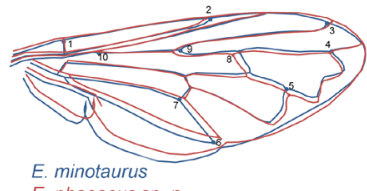

E. phaeacus sp. n.

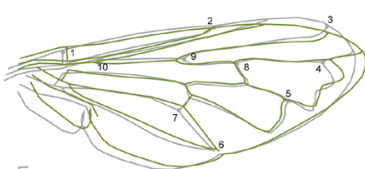

E. crassus

E. karyates sp. n.

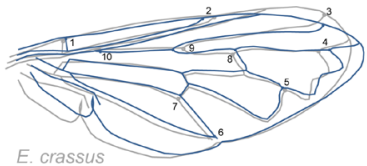

E. crassus

A

Figure 7. Wing shape differences among species of the Eumerus minotaurus group. A) Superimposed outline drawings showing differences in average wing shape for each species pair. Differences between the species were exaggerated three-fold to make them more visible; and B) UPGMA geo-phenogram constructed using the squared Mahalanobis distances of wing shape (for interpretation of the references to colour in this figure legend, the reader is asked to refer to the web version of this article).

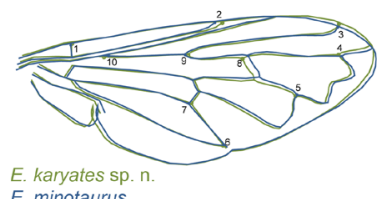

E. minotaurus

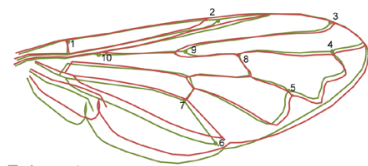

E. karyates sp. n.

E. phaeacus sp. n.

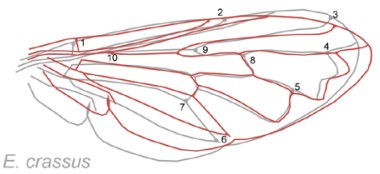

E. phaeacus sp. $\mathrm{n}$

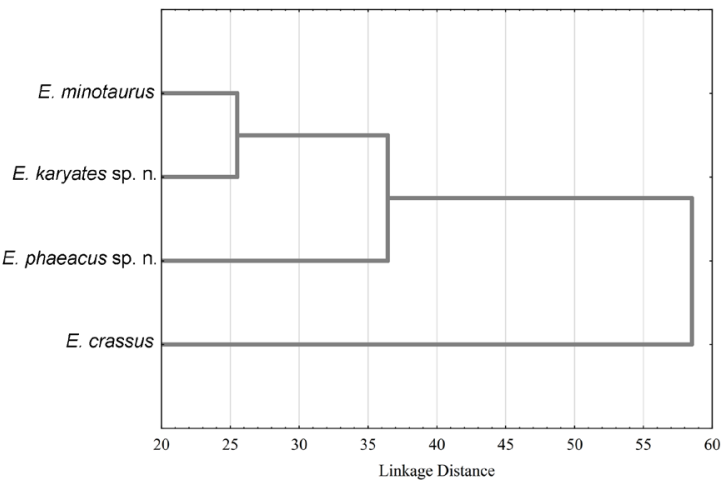

B 
Table 4. Results of simple and partial two-tailed Mantel tests for correlation among phenetic distance (wing shape) and genetic, geographic and climatic distances ( $p>0.05)$.

r

Simple Mantel test

wing - genetic

wing - geography

0.46

wing - climate

$-0.58$

Partial Mantel test

wing - genetic - holding geography

wing - genetic - holding climate

wing - geography holding genetic

$-0.57$

sp. n. were misclassified as E. phaeacus sp. n. A congruent classification was obtained by the Gaussian naive Bayes classifier, through which all specimens of E. minotaurus, E. crassus and E. phaeacus sp. n. were correctly classified, and only one specimen of E. karyates sp. n. was misclassified as E. minotaurus. The same male specimen of $E$. karyates sp. n. was misclassified by both approaches.

Superimposed outline drawings depict the differences in mean wing shape among each species (Figure 7A). The most obvious differences are among E. crassus and species of them $E$. minotaurus complex. In contrast, the most subtle differences in mean shape are between $E$. minotaurus and E. karyates sp. n. This is consistent with the results of our UPGMA analysis based on squared Mahalanobis distances (Figure 7B).

Correlation among wing shape, genetic, spatial and climatic differentiation

Simple Mantel tests revealed that genetic, geographic and climatic distances were not correlated with wing shape distance among E. minotaurus, E. karyates sp. n., E. phaeacus sp. n. or E. crassus (Table 4). Additionally, partial Mantel test showed that genetic distance has no impact on wing shape differentiation while accounting for geographic and environmental distances, nor did geographic while accounting for genetic distance (Table 4).

\section{Discussion}

Despite its critical role in ecosystems and the high species diversity of the genus Eumerus, which is continuously expanding through new species description, taxonomic issues remain. The new species within the genus (Doczkal 1996; Ricarte et al., 2012; Grković et al., 2015, 2017; Markov et al., 2016; van Steenis et al., 2017; Smit et al., 2017) should be incorporated into new phylogenetic and biogeographic studies. There has only been one phylogenetic study on the genus so far (Chroni et al., 2017), which provided genetic evidence of two major monophyletic lineages and seven 'molecular' groups within the genus Eumerus, including an $E$. minotaurus group.

The present study is the first to focus on the $E$. minotaurus group and, by employing an integrative framework, we reveal one new species and identify the E.minotaurus cryptic species complex within the genus (Figures 8,9). Evidence for the new species is based on morphological data, and the cryptic species complex is well supported by mtDNA sequences, discrete morphological features (antennae, male genitalia), wing morphometry, and biogeographic reconstructions. We also attempted, albeit unsuccessfully, to use a nuclear marker (never previously tried before in Eumerus) to infer phylogenetic relationships between species of the $E$. minotaurus group. Below, we discuss our findings and further conclude with contingent biogeographic patterns and speciation processes within the $E$. minotaurus group in relation to the palaeogeography of the Aegean region.

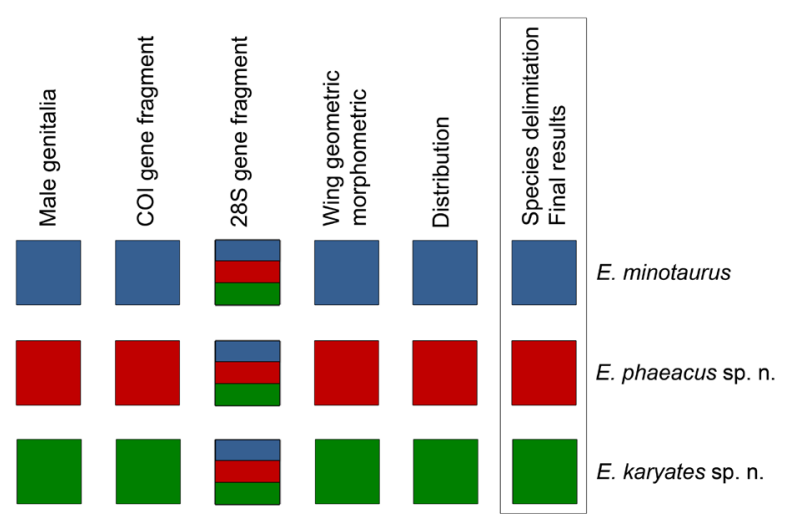

Figure 8. Summary of the results of integrative species delimitation within the Eumerus minotaurus complex: morphological characters (male genitalia), molecular markers (COI and 28S gene fragments), wing geometric morphometrics and geographical distribution. Each species is represented by a different colour; E. karyates sp. n. (green), E. minotaurus (blue) and E. phaeacus sp. n. (red). Solid colour boxes indicate successful species delimitation by particular approach. Multicolour boxes depict clusters formed by multiple species. 


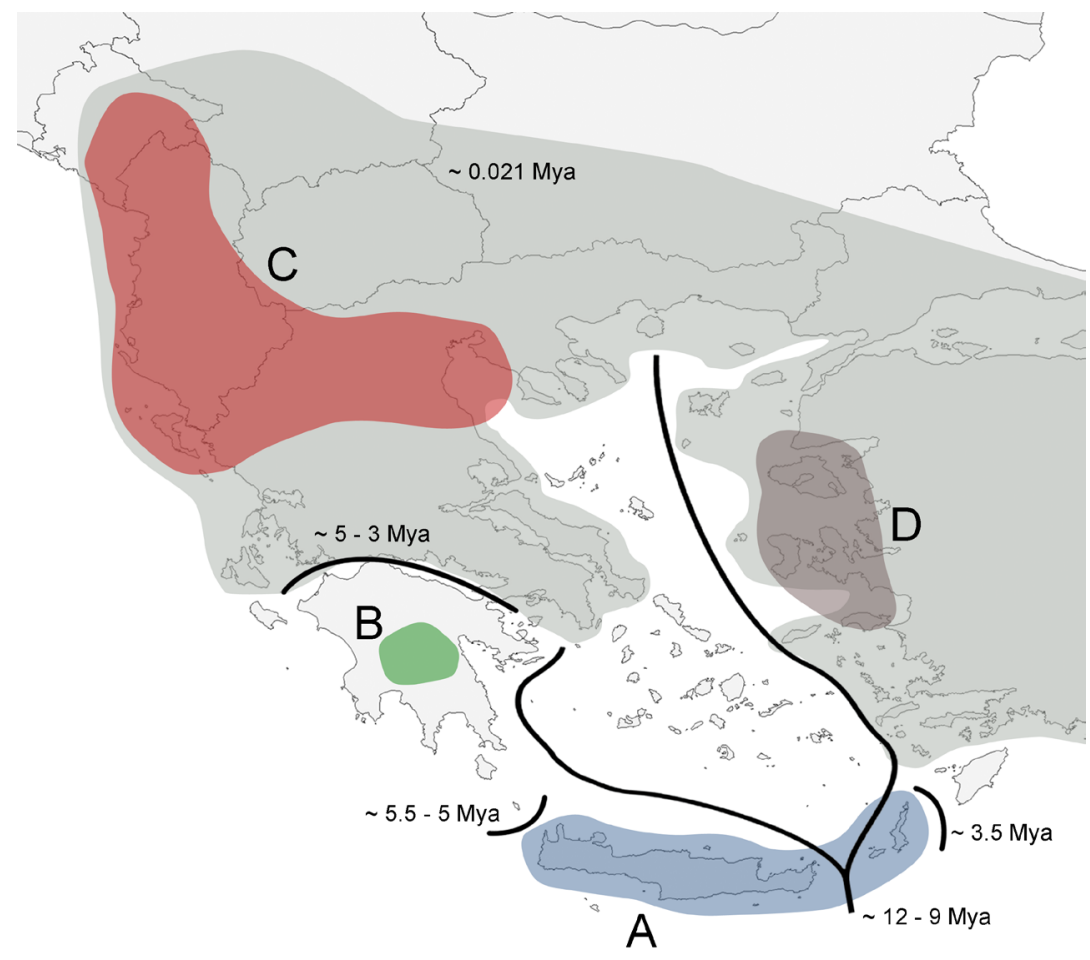

Figure 9. Mitochondrial phylogeographic pattern of the E. minotaurus taxon group. Specimens are grouped according to species/geographical cluster: E. crassus/ East Aegean Islands, D; E. karyates sp. n./Peloponnese, B; E. minotaurus/Crete and Karpathos, A; and E. phaeacus sp. n./Balkan peninsula, C. The major geological events in the Aegean Archipelago, that led to speciation within the group are displayed, i.e. the formation of MAT (12-9 Mya) and separations of: Crete from the Peloponnese (5.5-5 Mya), the Peloponnese from the Greek mainland (5-3 Mya) and Karpathos from Crete (3.5 Mya). There is evidence that until the end of the Pleistocene $(0.021$ Mya), the Greek mainland, Anatolia and the East Aegean Islands were still linked (for interpretation of the references to colour in this figure legend, the reader is referred to the web version of this article).

\section{Taxonomic and molecular implications}

Doczkal (1996) published the first study indicating the affinity among Eumerus species with elongated pedicels (i.e. the E. minotaurus group) in which he described E. niehuisi. Taxonomic and phylogenetic analyses of E. crassus, E. anatolicus sp. n., the $E$. minotaurus complex and $E$. longicornis have evidenced their differentiation from other Eumerus species (Doczkal, 1996; Chroni et al., 2017). We argue that all these aforementioned species belong to the same taxon group (the E. minotaurus group) owing to all of them having an elongated pedicel and similarly shaped male genitalia, the major common features differentiating them from other Eumerus species and groups. Studies by Hasson et al. (2009) and House et al. (2013) indicate that natural and sexual selection (and their interaction) may promote insect genital evolution.

Our morphology-based results are supported by our mtDNA analyses. The utility of a molecular marker is determined by its ability to reveal with high resolution the phylogenetic relationships of the organism(s) being studied, which is dependent on the mutation rate of the coding region. Our mtDNA phylogenetic reconstructions (tree-based species delimitation) and putative species limits analyses (non-tree-based) reaffirmed our morphological assignments (species predictions), clustering all these species within the same phylogenetic group with quite high bootstrap and probability values, and fully supporting the configuration of the E. minotaurus group. In addition, the employed mtDNA sequences clearly granted three lineages representing three different species within $E$. minotaurus, proving its suitability for resolving cryptic species. Identification of these three mitochondrial lineages led us to examine the male genitalia in more detail to seek subtle differences that we consider crucial to differentiating cryptic species. Tree topologies within the E. minotaurus group were consistent; in all cases, the E. crassus lineage was distinct from that of the E. minotaurus complex and, within the complex, E. karyates sp. n. and E. minotaurus clustered together but apart from E. phaeacus sp. n.

A combination of mitochondrial and nuclear gene fragments is often preferred to discriminate evolutionary lineages; therefore we intended to incorporate a nuclear marker dataset into our phylogenetic analyses. The 28S nuclear marker has shown genetic divergence among hoverflies (Mengual et al., 2008), and not only (e.g. Awasthi et al., 2016). However, in our study, the $28 \mathrm{~S}$ marker resulted in low tree resolution and lineage admixture. We detected partial (six out of 
eight sequences) clustering for one species of the $E$. minotaurus complex (E. karyates sp. n.) in the $28 \mathrm{~S}$ MP tree, denoting a recent speciation event, most likely not yet complete. For the remaining species of the E. minotaurus complex, the $28 \mathrm{~S}$ marker proved un-informative. We had only one $28 \mathrm{~S}$ sequence (that of E. crassus) outside of the E. minotaurus complex from which it was clearly separated, but the lack of sequences prevent us from making further conclusions about the utility of this marker for species diagnoses within Eumerus. We speculate that differences in lineage clustering in the trees generated by the two molecular markers are due to the faster evolutionary (mutation) rate of the mitochondrial gene fragment.

Our molecular and morphological inferences are also supported by highly significant morphological wing differentiation among species within the E. minotaurus complex. Although our species assignments for wing shape assessments were based on phylogenetic inferences, we consider wing shape heritability as a part of an integrative approach and a significant additive factor to our diagnosis of the cryptic species complex. Previous studies on hoverflies have shown that wing shape is a reliable predictor of interspecific differentiation, with wing geometric morphometry mainly being conducted on the genus Merodon (Milankov et al., 2009; Francuski et al., 2009, 2011; Ačanski et al., 2016; Šašić et al., 2016), but other examples of successful implementation of this method in hoverfly genera exist, such as in Cheilosia (Ludoški et al., 2008) and Chrysotoxum (Nedeljković et al., 2013; 2015), as well as in the hoverfly tribe Pipizini (Vujić et al., 2013). Moreover, in recent taxonomic studies of cryptic hoverfly species, molecular data strongly supported the results of geometric morphometrics results, even though small sample size was employed (as for the current study, Vujić et al., 2013; Nedeljković et al., 2013; 2015; Ačanski et al., 2016; Šašić et al., 2016; Radenković et al., 2017). This is the first study to include wing shape analyses on the genus Eumerus and the results are in accordance with previous hoverfly studies. Apart from the significant differences in wing shape among species, the high percentage of correct specimen assignments to species by both discriminant function analysis and the Gaussian naïve Bayes classifier analyses demonstrates that wing shape is highly reliable in cryptic species delimitation.

The topology of the phenogram based on wing shape variables was congruent with the topology inferred from phylogenetic analyses. The most similar wing shape was detected between E. minotaurus and E. karyates sp. n., and E. crassus wing shape was distinct from the species of the E. minotaurus complex. Observed differences in mean wing shape of the species within the E. minotaurus complex were mainly associated with broadness of the proximal part of the wing. Both proximal and distal parts of the wing differed between E. crassus and the E. minotaurus complex. Due to our small sample size, it was not possible to account for sexual dimorphism. Therefore, sexual dimorphism may bias some of our conclusions about mean wing shape differences among the investigated species. Wing length and width influence insect flight ability and male species-specific courtship song (Cowling and Burnet, 1981; Stubbs and Falk, 1983; Routtu et al., 2007; Sacchi and Hardersen, 2012; Menezes et al., 2013; Outomuro et al., 2013), indicating potential natural and sexual selection on wings. The Mantel tests (both simple and partial) we conducted showed no significant correlation among wing shape and current climate, or for geographic or genetic proximity. Following the statement and results mentioned above, we assume that interactions of natural selection, adaptive processes to paleogeographic conditions, phylogenetic history, and restricted gene flow of isolated ancestral populations could explain wing shape differences among the cryptic species.

\section{Mitochondrial dating, biogeographic history and di- vergence time estimates}

An important issue for the mitochondrial phylogeography of hoverflies (including Eumerus) is the absence of a fossil record and an accurate mitochondrial substitution rate for gene fragments that could be used to calibrate the molecular clock. Here, we essayed three different analytical approaches based on the two major geological events that occurred in the Aegean Archipelago (MAT and MSC) as well as the standard mitochondrial substitution rate reported for arthropods (mtDNA-rate, Brower, 1994). The mtDNA-rate is not always feasible for all insect groups, having been shown to produce unreliable results, and hence, potential pitfalls should be taken into account (Papadopoulou et al., 2010). Indeed, we found that the divergence times generated from our mtDNA-rate analysis were rather low and inconsistent with any major geological event of the Aegean region that could explain speciation within the E. minotaurus group, confirming its reputation to give 'unrealistic ages'. In contrast, the MAT and MAT\&MSC divergence 
time estimates were similar, with the latter approach being more in line with biogeographic events in the region. We posit that our MAT\&MSC divergence times might reflect better the actual diversification events. The low estimated pairwise substitution rates arising from the MAT and MAT\&MSC analyses are exceptional; low COI pairwise substitution rates have been found in other insects, such as ants $(1.5 \%$, Quek et al., 2004) and Drosophila species (1.54\%, Nunes et al., 2010), suggesting that caution should be exercised if calibrating the molecular clock according to the standard arthropod substitution rate of $2.3 \%$.

Heled and Drummond (2010) highlighted the necessity of assessing multiple samples per species when inferring speciation times and that 'two or more sequences per species are necessary for a complete estimation of speciation times, given enough loci'. We included from 4 to 18 sequences per species in our phylogenetic analyses with samples originating from different localities (except for E. karyates sp. n. that has only been recorded in Karyes of the Peloponnese, so all specimens were from one locality). Since the tree topology obtained from BEAST was congruent to those obtained from mitochondrial phylogenetic inferences (i.e., the COI dataset) and as the estimated molecular divergence times were concordant with the geological events that occurred in the Aegean region, we claim that our estimates for speciation events in the E. minotaurus group most likely reflect reality. Certainly, more sequences/taxa (or more loci) would further assist to elucidate the phylogeography of the $E$. minotaurus group but, unfortunately, insect sampling and gene amplification are always challenging.

Our phylogenetic assessment of the four species within the E.minotaurus group reflects their geographic distributions, with each species occurring in a specific region and belonging to a separate geographical cluster. As the initial diversification event occurred approximately 11.08 Mya (hereinafter, all timings are based on our MAT\&MSC analysis), we speculate that there was a single species during the Miocene in Ägäis, which served as the first ancestor of all species of the E. minotaurus group (as it is known today). When the MAT occurred, eastern populations split from western ones, with one population progressively dominating the eastern part of the Aegean to become E. crassus. Our biogeographic reconstructions suggest an east-to-west (from the East Aegean towards the Greek mainland and the Balkan Peninsula) species diversification of E. crassus, with dispersal and/or vicariant events, confirming the MAT scenario. In the biogeographic context, the Greek mainland was isolated from Anatolia and the East Aegean Islands at 0.18-0.14 Mya (and were most likely consolidated until the end of the Pleistocene at 0.021 Mya), and some of the Aegean Islands started to acquire their current configurations ca. 0.03-0.018 Mya and were finally shaped at 0.008 Mya (for a thorough review see Kougioumoutzis et al., 2017). We have estimated speciation of E. crassus at 0.91 Mya (mid-Pleistocene), reflecting a period of momentous geological and climatic changes in the Aegean that likely drove speciations and/or extinctions.

Another diversification event was detected at 7.6 Mya by our analyses that separated a northwestern population (Balkan Peninsula) from a southwestern one (Peloponnese/ Crete and Karpathos); our biogeographic analyses confirmed that "northto-south' division. Distribution patterns among the Aegean Islands are far more complex than those of the Ionian Islands because of their greater numbers and greater topographic, palaeogeographic, and environmental complexity (Gillespie and Clague, 2009; Kougioumoutzis et al., 2017). However, "the fauna and flora in the Ionian Islands are expected to be more 'harmonic', without profound gaps in their taxonomic composition" (Gillespie and Clague, 2009), harbouring fewer endemic taxa and existing taxa being more similar to those of the adjacent mainland. Indeed, E. phaeacus sp. n. is an insular (Corfu: Ionian Archipelago, Greece) and montane species (Balkan Peninsula: Mt Olympus, Greece; and Mt Rumija, Montenegro). Speciation forces similar to those that acted on E. crassus must have also influenced speciation of E. phaeacus sp. n. (estimated divergence at 0.67 Mya).

The Messinian Salinity Crisis was another major event that occurred in the Aegean, during which Crete became isolated from the Greek mainland but maintained a land connection to the Peloponnese until 5 Mya. Due to intense tectonic phenomena, the Aegean region was fragmented and considerably altered during the Pliocene. Crete became permanently isolated from the Peloponnese and other inland areas, and a wide sea-barrier (aka the Corinthian Channel) separated the Peloponnese from mainland Greece (5-3 Mya, Dermitzakis, 1990). Later, during the Pleistocene, climatic oscillations and sea-level fluctuations led to repeated connection/disconnection cycles (eight glacial cycles; for a review see Perissoratis and Conispoliatis, 2003), which altered the size and isolation of land areas (e.g. of the islands) by forming temporary land- 
bridges/corridors, allowing exchange of biota between islands and the mainland. These sea-level fluctuations continued until the late Pleistocene (0.021 Mya) and into the Holocene (Dermitzakis, 1990), inducing species diversification and dispersal (Perissoratis and Conispoliatis, 2003). A diversification event occurred 5.2 Mya within the southern populations of the $E$. minotaurus complex that subsequently gave rise to two species: E. karyates sp. n. (Peloponnese cluster) and E. minotaurus (Crete and Karpathos cluster). We have estimated the speciation events for these latter two species to date to 0.49 Mya and 2.26 Mya, respectively. We speculate that gene flow between the Peloponnese and Crete/Karpathos populations was impeded at the end of the MSC, when the Mediterranean Sea was refilled, and that speciation was favoured when the sea level started to stabilize. It is worth mentioning that the disconnection of Crete and Karpathos Islands (5-2 Mya) did not seem to affect the distribution of E. minotaurus (the same species is recorded on both islands), and no further speciation has taken place.

Among other phylogeographic studies carried out in the Aegean that explore the driving forces of animal speciation and biogeographic patterns, Poulakakis (2014) highlighted the importance of MAT for species distributions in the area. According to that study, species such as those of the E. minotaurus group can be characterized as post-MAT colonizers, describing them as "species that reached the region after the creation of the MAT, and whose diversification is due to the MSC, intense tectonism during the Pliocene and the climatic oscillations in these periods" (Poulakakis et al., 2014). Molecular clock is infrequently applied to insects groups in the Aegean, and when it does, it concerns mostly beetles (Papadopoulou et al., 2009; 2010), crickets (Allegrucci et al., 2009; 2011), termites (Luchetti et al., 2005; 2007) and sand fly (Kasap et al., 2015). Here, for the first time, we present phylogeographic and mitochondrial dating inferences about the hoverfly genus Eumerus in the Aegean, firmly supported by integrative taxonomic data, which may foster similar studies on other hoverfly genera to further elucidate the biogeographic evolution of the Aegean.

\section{Acknowledgements}

The authors would like to thank three anonymous reviewers for their valuable comments and suggestions that improved the quality of this paper. We thank John
O'Brien for proof reading and making constructive suggestions on the text. Financial support for this research was provided by the Serbian Ministry of Education, Science and Technological Development (Projects OI173002 and III43002) and the Provincial Secretariat for Science and Technological Development (Project 'Genetic resources of agro-ecosystems in Vojvodina and sustainable agriculture'), as well as the European Union (European Social Fund - ESF) and Greek national funds through the Operational Program 'Education and Lifelong Learning' of the National Strategic Reference Framework (NSRF) - Research Funding Program: THALES. Investing in knowledge society through the European Social Fund. We also acknowledge the Program «Grants IKY» of the State Scholarships Foundation of Greece, in the frame of the OP «Education and Lifelong Learning» of the European Social Fund (ESF) - NSRF, 2007-2013 (contract WP2-SHORT TERMS-19348) as partial financial support for the $\mathrm{PhD}$ thesis of $\mathrm{AC}$.

\section{References}

Ačanski J, Vujić A, Djan M, Obreht Vidaković D, Ståhls G, Radenković S. 2016. Defining species boundaries in the Merodon avidus complex (Diptera, Syrphidae) using integrative taxonomy, with a description of a new species. European Journal of Taxonomy 237: 1-25.

Ačanski J. 2017. Taxonomy and distribution of the genus Merodon Meigen (Diptera: Syrphidae) in Palearctic. PhD thesis (in Serbian), University of Novi Sad, Novi Sad, pp 209.

Akin C, Can Bilgin C, Beerli P, Westaway R, Ohst T, Litvinchuk SN, Uzzell T, Bilgin M, Hotz H, Guex GD, Plötner J. 2010. Phylogeographic patterns of genetic diversity in eastern Mediterranean water frogs were determined by geological processes and climate change in the Late Cenozoic. Journal of Biogeography 37: 2111-2124.

Allegrucci G, Rampini M, Gratton P, Todisco V, Sbordoni V. 2009. Testing phylogenetic hypotheses for reconstructing the evolutionary history of Dolichopoda cave crickets in the eastern Mediterranean. Journal of Biogeography 36: 17851797.

Allegrucci G, Trucchi E, Sbordoni V. 2011. Tempo and mode of species diversification in Dolichopoda cave crickets (Orthoptera, Rhaphidophoridae). Molecular Phylogenetics and Evolution 60: 108-121.

Arnqvist G, Mårtensson T. 1998. Measurement error in geometric morphometrics: empirical strategies to assess and reduce its impact on measures of shape. Acta Zoologica Academiae Scientiarum Hungaricae 44: 73-96.

Arzone A. 1973. Tragopon pratensis L., ospite naturale di Eumerus tricolor Meigen (Dipt. Syrphidae). Tipografia Vincenzo Bona, Torino 8:55-66.

Arzone A. 1971. Reperti biologici su Eumerus tricolor Meigen, nocivo alle coltivazioni di Tragopogon porrifolius L. in 
Piemonte (Dipt.Syrphidae). Tipografia Vincenzo Bona, Torino 7: 17-52.

Awasthi, M, Kashyap, A, Serajuddin, M. 2016. Molecular phylogeny of four gouramis based on divergent domain D11 of 28S rRNA gene. Advances in Biological Research 10: 351-353.

Ayres DL, Darling A, Zwickl DJ, Beerli P, Holder MT, Lewis PO, Huelsenbeck JP, Ronquist F, Swofford DL, Cummings MP, Rambaut A, Suchard MA. 2012. BEAGLE: an application programming interface and high-performance computing library for statistical phylogenetics. Systematic Biology 61: 170-173.

Baylac, M, Frieß, M. 2005. Fourier descriptors, Procrustes superimposition, and data dimensionality: an example of cranial shape analysis in modern human populations. In Modern morphometrics in physical anthropology. Springer, Boston, MA. 145-165.

Belshaw R, Fitton M, Herniou E, Gimeno C, Quicke DLJ. 1998. A phylogenetic reconstruction of the Ichneumonoidea (Hymenoptera) based on the D2 variable region of $28 \mathrm{~s}$ ribosomal RNA. Systematic Entomology 23: 109-123.

Bickford D, Lohman DJ, Navjot SS, Ng PKL, Meier R, Winker K, Ingram KK, Das I. 2007. Cryptic species as a window on diversity and conservation. Trends in Ecology and Evolution 22: 148-155.

Bofkin L, Goldman N. 2007. Variation in evolutionary processes at different codon positions. Molecular Biology and Evolution 24: 513-521.

Bonelli S, Witek M, Canterino, S, Sielezneiew M, StankiewiczFiedurek A, Tartally A, Balletto E, Schonrogge K. 2011. Distribution, host specificity, and the potential for cryptic speciation in hoverfly Microdon myrmicae (Diptera: Syrphidae), a social parasite of Myrmica ants. Ecological Entomology 36: 135-143.

Brower AVZ. 1994. Rapid morphological radiation and convergence among races of the butterfly Heliconius erato inferred from patterns of mitochondrial DNA evolution. Proceedings of the National Academy of Sciences USA 91: 6491-6495.

Brummitt RK, Pando F, Hollis S, Brummitt NA. 2001. World geographical scheme for recording plant distributions. International Working Group on Taxonomic Databases for Plant Sciences (TDWG).

Chen H, Rangasamy M, Tan SY, Wang HC, Siegfried BD. 2010. Evaluation of five methods for total DNA extraction from western corn rootworm beetles. PLoS One 5: 1-6.

Chroni A, Djan M, Vidaković DO, Petanidou T, Vujić A. 2017. Molecular species delimitation in the genus Eumerus (Diptera: Syrphidae). Bulletin of Entomological Research 107: 126-138.

Clement M, Posada D, Crandall KA. 2000. TCS: a computer program to estimate gene genealogies. Molecular Ecology 9: 1657-1660.

Cowling DE, Burnet B. 1981. Courtship songs and genetic control of their acoustic characteristics in sibling species of the Drosophila melanogaster subgroup. Animal Behaviour 29: 924-935

Dayrat B. 2005. Towards integrative taxonomy.Biological Journal of the Linnean Society 85: 407-415.

Dell Statistica. 2015. Dell Statistica data analysis software system, version 13. Dell Inc.
Dermitzakis MD. 1990. Paleogeography, geodynamic processes and event stratigraphy during the Late Cenozoic of the Aegean area. Accademia Nazionale dei Lincei 85: 263-288.

Dias VS, Silva JG, Lima KM, Petitinga CSCD, HernándezOrtiz V, Laumann RA, Paranhos BJ, Uramoto K, Zucchi RA, Joachim-Bravo IS. 2016. An integrative multidisciplinary approach to understanding cryptic divergence in Brazilian species of the Anastrepha fraterculus complex (Diptera: Tephritidae). Biological Journal of the Linnean Society 117: 725-746.

Diaz SA, Moncada LI, Murcia CH, Lotta IA, Matta NE, Adler PH. 2015. Integrated taxonomy of a new species of black fly in the subgenus Trichodagmia (Diptera: Simuliidae) from the Páramo Region of Colombia. Zootaxa 3914: 541-57.

Doczkal D. 1996. Description of two new species of the genus Eumerus Meigen (Dipt., Syrph.) from Corsica. Volucella 2: 3-19.

Drummond AJ, Suchard MA, Xie D, Rambaut A. 2012. Bayesian phylogenetics with BEAUti and the BEAST 1.7. Molecular Biology and Evolution 29: 1969-1973.

Folmer O, Black M, Hoeh W, Lutz R, Vrijenhoek R. 1994. DNA primers for amplification of mitochondrial cytochrome c oxidase subunit I from diverse metazoan invertebrates. Molecular Marine Biology and Biotechnology 3: 294-299.

Francuski L, Ludoški J, Vujić A, Milankov V. 2009. Wing geometric morphometric inferences on species delimitation and intraspecific divergent units in the Merodon ruficornis group (Diptera, Syrphidae) from the Balkan Peninsula. Zoological Science 26: 301-308.

Francuski L, Ludoški J, Vujić A, Milankov V. 2011. Phenotypic evidence for hidden biodiversity in the Merodon aureus group (Diptera, Syrphidae) on the Balkan Peninsula: conservation implication. Journal of Insect Conservation 15: 379-388.

Gillespie RG, Clague DA. 2009. Encyclopedia of Islands. No. 2.Univ of California Press.

Gkontas I, Papadaki S, Trichas A, Poulakakis N. 2016. First assessment on the molecular phylogeny and phylogeography of the species Gnaptor boryi distributed in Greece (Coleoptera: Tenebrionidae). Mitochondrial DNA Part A 1-8. http://dx.doi.org/10.1080/24701394.2016.1209196

Goloboff PA. 1999. NONA (NO NAME), version 2 [computer program]. Tucumán, Argentina: The Author.

Grković A, Vujić A, Radenković S, Chroni A, Petanidou T. 2015. Diversity of the genus Eumerus Meigen (Diptera, Syrphidae) on the eastern Mediterranean islands with description of three new species. Annales de la Société Entomologique de France 51: 361-373.

Grković A, Vujić A, Chroni A, van Steenis J, Đan M, Radenković S. 2017. Taxonomy and systematics of three species of the genus Eumerus Meigen, 1822 (Diptera: Syrphidae) new in southeastern Europe. Zoologischer Anzeiger 270: 176-192, https://doi.org/10.1016/j.jcz.2017.10.007

Hall TA. 1999. BioEdit: a user-friendly biological sequence alignment editor and analysis program for Windows 95/98/ NT. Nucleic Acids Symposium Series 41: 95-98.

Hasson E, Soto IM, Carreira VP, Corio C, Soto EM, Betti M. 2009. Host plants, fitness and developmental instability in a guild of cactophilic species of the genus Drosophila. Pp. 89-109 in: Santos EB, ed., Ecotoxicology Research Developments. New York: Nova Science Publishers.

Hebert PD, Cywinska A, Ball SL, deWaard JR. 2003. Biological 
identifications through DNA barcodes. Proceedings of the Royal Society B 270: 313-321.

Heled J, Drummond AJ. 2010. Bayesian inference of species trees from multilocus data. Molecular Biology and Evolution 27: $570-580$.

Hijmans RJ, Cameron SE, Parra JL, Jones PG, Jarvis A. 2005. Very high resolution interpolated climate surfaces for global land areas. International Journal of Climatology 25: 19651978.

House CM, Lewis Z, Hodgson DJ, Wedell N, Sharma MD, Hunt J, Hosken DJ. 2013. Sexual and natural selection both influence male genital evolution. PLoS One 8: e63807. https://doi.org/10.1371/journal.pone.0063807

Huelsenbeck JP, Ronquist F. 2001. MRBAYES: bayesian inference of phylogenetic trees. Bioinformatics 17: 754-755.

Hurkmans W. 1993. A monograph of Merodon (Diptera: Syrphidae). Part 1. Tijdschrift voor Entomologie 136: 147234.

Huson DH, Bryant D. 2006. Application of phylogenetic networks in evolutionary studies, Molecular Biology and Evolution 23: 254-267.

Kamilari M, Klossa Kilia E, Kilias G, Sfenthourakis S. 2014. Old Aegean palaeoevents driving the diversification of an endemic isopod species (Oniscidea, Trachelipodidae). Zoologica Scripta 43: 379-92.

Kasap OE, Dvorak V, Depaquit J, Alten B, Votypka J, Volf P. 2015. Phylogeography of the subgenus Transphlebotomus Artemiev with description of two new species, Phlebotomus anatolicus n. sp. and Phlebotomus killicki n. sp. Infection, Genetics and Evolution 34: 467-79.

Kasapidis P, Magoulas A, Mylonas M, Zouros E. 2005. The phylogeography of the gecko Cyrtopodion kotschyi (Reptilia: Gekkonidae) in the Aegean Archipelago. Molecular Phylogenetics and Evolution 35: 612-623.

Katoh K, Kuma K, Toh H, Miyata T. 2005. MAFFT version 5: improvement in accuracy of multiple sequence alignment. Nucleic Acids Research 33: 511-518.

Kirichenko N, Huemer P, Deutsch H, Triberti P, Rougerie R, Lopez-Vaamonde C. 2015. Integrative taxonomy reveals a new species of Callisto (Lepidoptera, Gracillariidae) in the Alps. ZooKeys 473: 157-176.

Klingenberg CP. 2011. MORPHOJ: an integrated software package for geometric morphometrics. Ver.2.0. Molecular Ecology Resources 11: 353-357.

Kougioumoutzis K, Valli AT, Georgopoulou E, Simaiakis S, Triantis KA, Trigas P. 2017. Network biogeography of a complex island system: the Aegean archipelago revisited. Journal of Biogeography 44: 651-660.

Librado P, Rozas J. 2009. DnaSP v5: a software for comprehensive analysis of DNA polymorphism data. Bioinformatics 25: 1451-1452.

Luchetti A, Marini M, Mantovani B. 2005. Mitochondrial evolutionary rate and speciation in termites: data on European Reticulitermes taxa (Isoptera, Rhinotermitidae). Insectes Sociaux 52: 218-221.

Luchetti A, Marini M, Mantovani B. 2007. Filling the European gap: biosystematics of the eusocial system Reticulitermes (Isoptera, Rhinotermitidae) in the Balkanic Peninsula and Aegean area. Molecular Phylogenetics and Evolution 45: 377-383.

Ludoški J, Francuski L, Vujić A, Milankov V. 2008. The
Cheilosia canicularis group (Diptera: Syrphidae): species delimitation and evolutionary relationships based on wing geometric morphometrics. Zootaxa 1825: 40-50.

Mantel NA. 1967. The detection of disease clustering and a generalized regression approach. Cancer Research 27: 209220.

Markov Z, Nedeljković Z, Ricarte A, Vujić A, Jovičić S, Józan Z, Mudri-Stojnić S, Radenković S, Ćetković A. 2016. Bee (Hymenoptera: Apoidea) and hoverfly (Diptera: Syrphidae) pollinators in Pannonian habitats of Serbia, with a description of a new Eumerus Meigen species (Syrphidae). Zootaxa 4154: 027-050.

Martinsson S, Erséus C. 2017. Cryptic speciation and limited hybridization within Lumbricus earthworms (Clitellata: Lumbricidae). Molecular Phylogenetics and Evolution 106:18-27.

Menezes BF, Vigoder FM, Peixoto AA, Varaldi J, Bitner-Mathé BC. 2013. The influence of male wing shape on mating success in Drosophila melanogaster. Animal Behaviour 85: 1217-1223.

Mengual, X, Ståhls, G, Rojo, S. 2008. First phylogeny of predatory flower flies (Diptera, Syrphidae, Syrphinae) using mitochondrial COI and nuclear 28S rRNA genes: conflict and congruence with the current tribal classification. Cladistics 24: $543-562$.

Mezey JG, Houle D. 2005. The dimensionality of genetic variation for wing shape in Drosophila melanogaster. Evolution 59: 1027-1038.

Milankov V, Ludoški J, Ståhls G, Stamenković J, Vujić A. 2009. High molecular and phenotypic diversity in the Merodon avidus complex (Diptera, Syrphidae): cryptic speciation in a diverse insect taxon. Zoological Journal of the Linnean Society 155: 819-833.

Miller MA, Pfeiffer W, Schwartz T. 2010. Creating the CIPRES Science Gateway for inference of large phylogenetic trees. In: 2010 Gateway Computing Environments Workshop, GCE 2010.

Moraes EM, Manfrin MH, Laus AC, Rosada RS, Bomfin SC, Sene FM. 2004.Wing shape heritability and morphological divergence of the sibling species Drosophila mercatorum and Drosophila paranaensis. Heredity 92: 466-473.

Nedeljković Z, Ačanski J, Vujić A, Obreht D, Dan M, Ståhls G, Radenković S. 2013. Taxonomy of Chrysotoxum festivum Linnaeus, 1758 (Diptera: Syrphidae) - an integrative approach. Zoological Journal of the Linnean Society 169: 84-102.

Nedeljković Z, Ačanski J, Dan M, Obreht-Vidaković D, Ricarte A, Vujić A. 2015. An integrated approach to delimiting species borders in the genus Chrysotoxum Meigen, 1803 (Diptera: Syrphidae), with description of two new species. Contributions to Zoology 84: 285-304.

Nixon KC. 2002. WinClada ver. 1.00.08. Published by author, Ithaca, NY.

Nunes MD, Orozco-Ter Wengel PA, Kreissl M, Schlötterer C. 2010. Multiple hybridization events between Drosophila simulans and Drosophila mauritiana are supported by mtDNA introgression. Molecular Ecology 19: 4695-707.

Outomuro D,Adams DC, Johansson F.2013. The evolution of wing shape in ornamented-winged damselflies (Calopterygidae, Odonata). Evolutionary biology 40: 300-309.

Padial JM, Miralles A, de la Riva I, Vences M. 2010. The 
integrative future of taxonomy. Frontiers in Zoology 7: 16.

Papadopoulou A, Anastasiou I, Keskin B, Vogler AP. 2009. Comparative phylogeography of tenebrionid beetles in the Aegean archipelago: the effect of dispersal ability and habitat preference. Molecular Ecology 18: 2503-2517.

Papadopoulou A, Anastasiou I, Vogler AP. 2010. Revisiting the insect mitochondrial molecular clock: the mid-Aegean trench calibration. Molecular Biology and Evolution 27: 1659-1672.

Papakostas S, Michaloudi E, Proios K, Brehm M, Verhage L, Rota J, Peña C, Stamou G, Pritchard VL, Fontaneto D, Declerck SAJ. 2016. Integrative taxonomy recognizes evolutionary Units despite widespread mitonuclear discordance: evidence from a rotifer cryptic species complex. Systematic Biology 65: 508-524.

Pape T, Thompson FC (eds). 2015. Systema Dipterorum. Version 1.5.Available online at http://www.diptera.org/

Parmakelis A, Stathi I, Chatzaki M, Simaiakis S, Spanos L, Louis C, Mylonas M. 2006. Evolution of Mesobuthus gibbosus (Brulle, 1832) (Scorpiones: Buthidae) in the northeastern Mediterranean region. Molecular Ecology 15: 2883-2894.

Perez MF, Carstens BC, Rodrigues GL, Moraes EM. 2016. Anonymous nuclear markers data supporting species tree phylogeny and divergence time estimates in a cactus species complex in South America. Data Brief 6: 456-460.

Pérez-Bañón C, Marcos-García A. 1998. Life history and description of the immature stages of Eumerus purpurariae (Diptera: Syrphidae) developing in Opuntia maxima. European Journal of Entomology 95: 373-82.

Pérez-Ponce de León G, Nadler SA. 2010. What we don't recognize can hurt us: A plea for awareness about cryptic species. Journal of Parasitology 96: 453-464.

Perissoratis C, Conispoliatis N. 2003. The impacts of sea-level changes during latest Pleistocene and Holocene times on the morphology of the Ionian and Aegean seas (SE Alpine Europe). Marine Geology 196: 145-156.

Petanidou T, Vujić A, Ellis WN. 2011. Hoverfly diversity (Diptera: Syrphidae) in a Mediterranean scrub community near Athens, Greece. Annales de la Société Entomologique de France 47: 168-175.

Pfenninger M, Schwenk K. 2007. Cryptic animal species are homogeneously distributed among taxa and biogeographical regions. Journal of Evolutionary Biology 7: 121.

Popović D, Ačanski J, Djan M, Obreht D, Vujić A, Radenković S. 2015. Sibling species delimitation and nomenclature of the Merodon avidus complex (Diptera: Syrphidae). European Journal of Entomology 112: 790-809.

Posada D, Crandall KA. 2001. Evaluation of methods for detecting recombination from DNA sequences: computer simulations. Proceedings of the National Academy of Sciences USA 98: 13757-13762.

Poulakakis N, Lymberakis P, Valakos E, Pafilis P, Zouros E, Mylonas M. 2005. Phylogeography of Balkan wall lizard (Podarcis taurica) and its relatives inferred from mitochondrial DNA sequences. Molecular Ecology 14: 2433-2443.

Poulakakis N, Sfenthourakis S. 2008. Molecular phylogeny and phylogeography of the Greek populations of the genus Orthometopon (Isopoda, Oniscidea) based on mitochondrial DNA sequences. Zoological Journal of the Linnean Society 152: 707-715.
Poulakakis N, Kapli P, Lymberakis P, Trichas A, Vardinoyiannis K, Sfenthourakis S, Mylonas M. 2015. A review of phylogeographic analyses of animal taxa from the Aegean and surrounding regions. Journal of Zoological Systematics and Evolutionary Research 53: 18-32.

Puillandre N, Stöcklin R, Favreau P, Bianchi E, Perret F, Rivasseau A, Limpalaër L, Monnier E, Bouchet P. 2014. When everything converges: Integrative taxonomy with shell, DNA and venomic data reveals Conus conco, a new species of cone snails (Gastropoda: Conoidea). Molecular Phylogenetics and Evolution 80: 186-92.

Quantum GIS Development Team. 2012. Quantum GIS Geographic Information System. Version 2.12.3 Lyon [Internet]. Open Source Geospatial Foundation Project, available at http://qgis.osgeo.org.

Quek SP, Davies SJ, Itino T, Pierce NE. 2004. Codiversification in an ant-plant mutualism: stem texture and the evolution of host use in Crematogaster (Formicidae: Myrmicinae) inhabitants of Macaranga (Euphorbiaceae). Evolution 58: 554-70.

Radenković S, Šašić Zorić L, Djan M, Obreht Vidaković D, Ačanski J, Ståhls G, Veličković N, Markov Z, Petanidou T, Kočiš Tubić N, Vujić A. 2017. Cryptic speciation in the Merodon luteomaculatus complex (Diptera: Syrphidae) from the eastern Mediterranean. Journal of Zoological Systematics and Evolutionary Research: 1-22.

Rambaut A. 2013. FigTree, http://tree.bio.ed.ac.uk/software/ figtree/

Rambaut A, Suchard MA, Xie D, Drummond AJ. 2014. Tracer v1.6. http://tree.bio.ed.ac.uk/software/tracer/

Rambaut A, Lam TT, Carvalho LM, Pybus OG. 2016. Exploring the temporal structure of heterochronous sequences using TempEst (formerly Path-O-Gen). Virus Evolution 2: vew007.

Ratnasingham S, Hebert PDN. 2013. A DNA-based registry for all animal species: the Barcode Index Number (BIN) system. PLOS ONE 8: e66213.

Rato C, Harris DJ, Carranza S, Machado L, Perera A. 2016. The taxonomy of the Tarentola mauritanica species complex (Gekkota: Phyllodactylidae): Bayesian species delimitation supports six candidate species. Molecular Phylogenetics and Evolution 94: 271-278.

Ricarte A, Nedeljković Z, Rotheray GE, Yszkowski RM, Hancock EG, Watt K, Hewitt SM, Horsefield D, Wilkinson G. 2012. Syrphidae (Diptera) from the Greek island of Lesvos, with description of two new species. Zootaxa 317:123.

Rodriguez F, Oliver JL, Marin A, Medina JR. 1990. The general stochastic-model of nucleotide substitution. Journal of Theoretical Biology 142: 485-501.

Rohlf FJ. 2006. TpsDig-Digitize landmarks and outlines. Ver.2.05. New York: Department of Ecology and Evolution, State University of New York at Stony Brook.

Rohlf FJ, Slice DE. 1990. Extensions of the Procrustes method for the optimal superimposition of landmarks. Systematic Zoology 39: 40-59.

Ronquist F, Huelsenbeck JP. 2003. MrBayes3: Bayesian phylogenetic inference undermixed models. Bioinformatics 19: 1572-1574.

Rosenberg MS, Anderson CD. 2011. PASSaGE: Pattern Analysis, Spatial Statistics and Geographic Exegesis. Version 2. Methods in Ecology and Evolution 2: 229-232. 
Rotheray GE, Gilbert F. 2011. The Natural History of Hoverflies. UK, Ceredigion.

Routtu J, Mazzi D, Van Der Linde K, Mirol P, Butlin RK, Hoikkala A. 2007. The extent of variation in male song, wing and genital characters among allopatric Drosophila montana populations. Journal of evolutionary biology 20: 1591-1601.

Sacchi R, Hardersen S. 2013. Wing length allometry in Odonata: differences between families in relation to migratory behaviour. Zoomorphology 132: 23-32.

Šašić L, Ačanski J, Vujić A, Ståhls G, Radenković S, Milić D, Vidaković DO, Đan M. 2016. Molecular and morphological inference of three cryptic species within the Merodon aureus species group (Diptera: Syrphidae). PLOS ONE 11: e0160001.

Schlick-Steiner BC, Steiner FM, Seifert B, Stauffer C, Christian E, Crozier RH. 2010. Integrative taxonomy: a multisource approach to exploring Biodiversity. Annual Review of Entomology 55: 421-438.

Sfenthourakis S, Triantis KA. 2017. The Aegean archipelago: a natural laboratory of evolution, ecology and civilisations. Journal of Biological Research-Thessaloniki 24: 4.

Shapiro B, Rambaut A, Drummond AJ. 2006. Choosing appropriate substitution models for the phylogenetic analysis of protein-coding sequences. Molecular Biology and Evolution 23: 7-9.

Sheets HD. 2012. IMP software series. Buffalo, New York: Canisius College.

Simaiakis SM, Dimopoulou A, Mitrakos A, Mylonas M, Parmakelis A. 2012. The evolutionary history of the Mediterranean centipede Scolopendra cingulata (Latreille, 1829) (Chilopoda: Scolopendridae) across the Aegean archipelago. Biological Journal of the Linnean Society 105: 507-521.

Simmons MP, Zhang LB, Webb CT, Reeves A. 2006. How can third codon positions outperform first and second codon positions in phylogenetic inference? An empirical example from the seed plants. Systematic Biology 55: 245-58.

Simon C, Frati F, Beckenbach A, Crespi B, Liu H, Flook P. 1994. Evolution, weighting, and phylogenetic utility of mitochondrial gene-sequences and a compilation of conserved polymerase chain-reaction primers. Annals of the Entomological Society of America 87: 651-701.

Smit JT, van Harten A, Ketelaar R. 2017. The hoverflies of the Arabian Peninsula. In: Arthropod fauna of the UAE, Chapter: Order Diptera, Family Syrphidae. Eds. Tony van Harten, 572-612.

Soldati L, Kergoat GJ, Clamens AL, Jourdan H, JabbourZahab R, Condamine FL. 2014. Integrative taxonomy of New Caledonian beetles: species delimitation and definition of the Uloma isoceroides species group (Coleoptera, Tenebrionidae, Ulomini), with the description of four new species. ZooKeys 415: 133-167.

Speight MCD, Hauser M, Withers P. 2013. Eumerus narcissi Smith (Diptera, Syrphidae), presence in Europe confirmed, with a redescription of the species. Dipterist Digest 20: 17-32.

Speight, MCD 2016. Species accounts of European Syrphidae (Diptera). Syrph the Net, the database of European Syrphidae. Dublin. 93: Syrph the Net publications pp. 288.

Stackelberg AA. 1961. Palaearctic species of the genus Eumerus Mg. (Diptera, Syrphidae). Trudy Vsesojuznogo Entomologiceskogo Obscestva 48, 181-229.
Stamatakis A. 2006. RAxML-VI-HPC: Maximum likelihoodbased phylogenetic analyses with thousands of taxa and mixed models. Bioinformatics 22: 2688-2690.

Stamatakis A, Hoover P, Rougemont J. 2008.A rapid bootstrap algorithm for the RAxML Web servers. Systematic Biology 57: 758-71.

Strasser TF, Panagopoulou E, Runnels CN, Murray PM, Thompson N, Karkanas P, McCoy FW, Wegmann KW. 2010. Stone Age seafaring in the Mediterranean: evidence from the Plakias region for lower palaeolithic and mesolithic habitation of Crete. Hesperia 79: 145-190.

Strid A. 2016. Atlas of the Aegean flora. Englera 33: 1-578.

Stubbs AE, Falk S. 1983. British hoverflies: an illustrated guide. British Entomological and Natural History Society, London.

Tamura K, Stecher G, Peterson D, Filipski A, Kumar S. 2013. MEGA6: Molecular Evolutionary Genetics Analysis Version 6.0. Molecular Biology and Evolution 30: 2725-2729.

Thompson CF. 1999. A key to the genera of the flower flies (Diptera: Syrphidae) of the Neotropical Region including descriptions of new genera and species and a glossary of taxonomic terms. Contributions on Entomology International 3: 319-378.

van Steenis J, Hauser M, van Zuijen MP. 2017. Review of the Eumerus barbarus species group (Diptera: Syrphidae) from the western Mediterranean Basin. Bonn Zoological Bulletin 66: 145-165.

Vujić A, Ståhls G, Ačanski J, Bartsch H, Bygebjerg R, Stefanović A. 2013. Systematics of Pipizini and taxonomy of European Pipiza Fallen: molecular and morphological evidence (Diptera, Syrphidae). Zoologica Scripta 42: 288-305.

Vujić A, Radenković S, Ačanski J, Grković A, Taylor M, Şenol SG, Hayat R. 2014. Revision of the species of the Merodon nanus group (Diptera: Syrphidae) including three new species. Zootaxa 4006: 439-462.

Yeaman S, Chen Y, Whitlock MC. 2010. No effect of environmental heterogeneity on the maintenance of genetic variation in wing shape in Drosophila melanogaster. Evolution 64: 3398-3408.

Yu Y, Harris AJ, Blair C, He XJ. 2015. RASP (Reconstruct Ancestral State in Phylogenies): a tool for historical biogeography. Molecular Phylogenetics and Evolution 87: 46-49.

Zelditch ML, Swiderski DL, Sheets HD, Fink WL. 2004. Geometric morphometrics for biologists: a primer. London: Elsevier Academic Press.

Zhang JJ, Kapli P, Pavlidis P, Stamatakis A. 2013. A general species delimitation method with applications to phylogenetic placements. Bioinformatics 29: 2869-2876.

Received: 5 March 2018

Revised and accepted: 7 August 2018

Published online: 2 November 2018

Editor: A. Ivanović 


\section{Online supplementary information}

S1. List of specimens used for wing geometric morphometric analysis by geographical area and species.

S2. Maximum likelihood analysis for the concatenated 3 ' and $5^{\prime}$ fragments of the COI gene (COI dataset). Values above branches indicate bootstrap replicates (only values $>50$ are illustrated).

S3. Neighbor-joining analysis for the concatenated 3' and 5' fragments of the COI gene (COI dataset). Values in the branches indicate bootstrap replicates (only values $>50$ are illustrated).

S4. Bayesian analysis for the concatenated 3 ' and 5' fragments of the COI gene (COI dataset). Values indicate Bayesian probabilities.
S5. Haplotype networks constructed using the statistical parsimony algorithm for the concatenated 3' and 5' fragments of the COI gene (COI subset) for the E. minotaurus group.

S6. Maximum parsimony analysis of the $28 \mathrm{~S}$ gene fragment (28S dataset). Only one tree was generated (Length 90 steps, CI=93, RI=81). Filled circles denote unique changes and open circles are non-unique changes. Bootstrap support values are illustrated above the branches.

S7. Results of Principal component analysis conducted on wing shape variables.

S8. Results of discriminant analysis conducted on wing shape variables. $F$ values are shown above the diagonal, $\mathrm{p}$ values are shown below the diagonal ( $\mathrm{df}$ $=13.35$ ). 


\section{Appendix}

\section{Systematics}

\section{Eumerus minotaurus group}

Diagnosis. Species with elongated pedicel, at least 1.5 times longer than deep. Short body pile. Metafemur moderately swollen. Ventral pile on metafemur not longer than half the depth of the femur. Abdomen black with bronze to gold tinge laterally, about two times as long as wide. S4 in males flat, with invaginated posterior margin (Figure 10K), very similar in shape in all species of the group. Posterior surstyle lobe in males genitalia simple, oval (Figure 10A-C); hardly varying in shape between species, except for $E$. crassus and E. niehuisi (slightly different). The group includes the following species in Europe: E. crassus

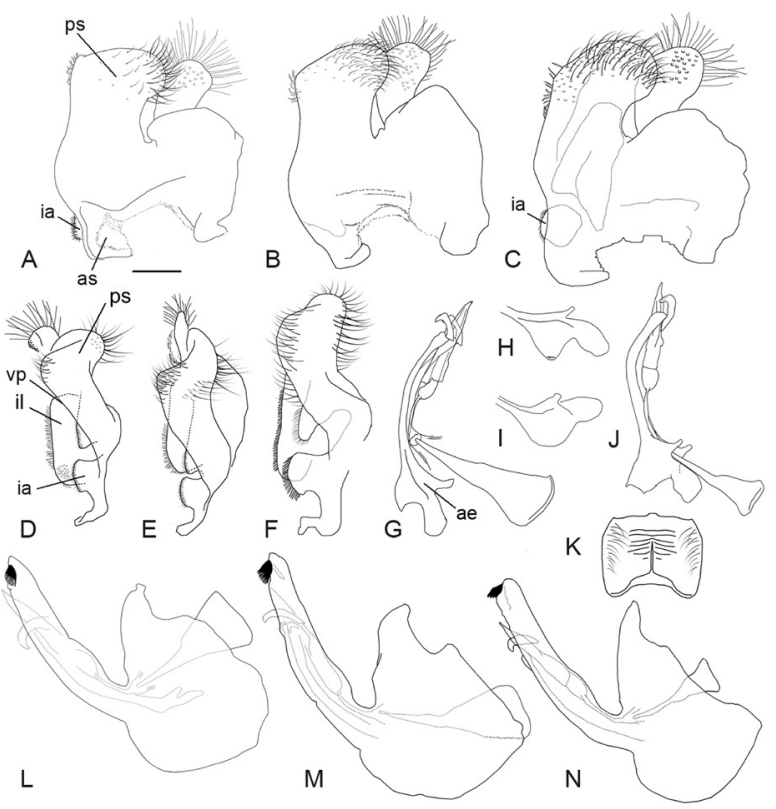

Figure 10. Male genitalia. Epandrium, lateral view: A) E. minotaurus complex, B) E. longicornis Loew, 1855, C) E. anatolicus sp. n., ventral view: D) E. minotaurus complex, E) E. longicornis, F) E. anatolicus sp. n.; G) E. minotaurus Claussen and Lucas, 1988, aedeagus with accessory structures; distal part of aedeagal apodeme: H) E. karyates sp.n., I) E. phaeacus sp.n., J) E. anatolicus sp. n., aedeagus with accessory structures; K) $E$. minotaurus complex, males abdominal sternite IV; hypandrium, lateral view: L) E. minotaurus complex, M) E. longicornis, N) E. anatolicus sp. n. Scale $0.2 \mathrm{~mm}$. ae - aedeagal apodeme, as - anterior lobe of surstylus, il - interior lobe of posterior lobe of surstylus, ia - inner lobe of anterior lobe of surstylus, ps posterior lobe of surstylus, $\mathrm{vp}-$ ventral margin of posterior surstyle lobe.

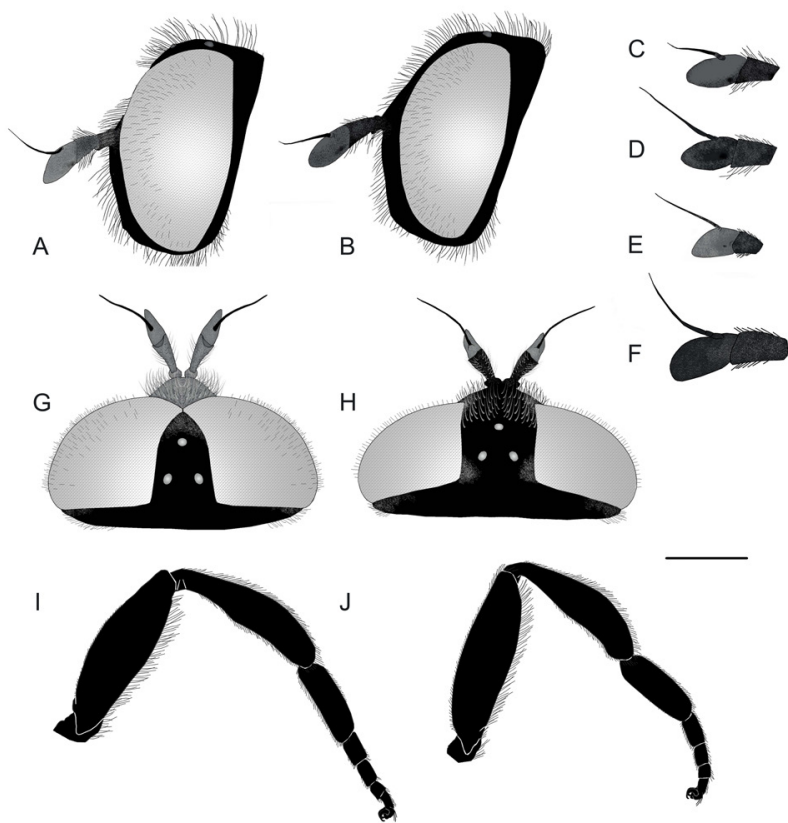

Figure 11. E. minotaurus group, head, lateral view: A) E. minotaurus Claussen and Lucas, 1988, male, B) E. phaeacus sp. n., female; antenna: C) E. karyates sp. n., D) E. anatolicus sp. n., E) E. crassus Grković, Vujić and Radenković, 2015, F) E. longicornis Loew, 1855; dorsal view: G) E. minotaurus, male, H) E. phaeacus sp. n., female. E. minotaurus complex, leg: I) male, J) female. Scale: $1 \mathrm{~mm}$.

(Figure 11E), E. longicornis (Figures 10B, E, M, 11F), $E$. niehuisi and the E. minotaurus cryptic species complex (comprising E. karyates sp. n., E. minotaurus and $E$. phaeacus sp.n.; hereafter named E. minotaurus complex); and in Turkey: E. anatolicus sp. n. and E. crassus.

\section{Eumerus minotaurus cryptic species complex}

Diagnosis. Dark appearance, body blackish-bronze. Eyes covered with long white scattered pilosity (Figure 11G, H), whereas eyes in E. longicornis are almost bare. Second and third antennal segment elongated, with almost the same width (Figure 11AC), similar to E. longicornis but the ventral margin of the basoflagellomere of this latter species is linear (Figure 11F) whereas it is slightly convex in the $E$. minotaurus complex. White to grey, very narrow and linear pollinose maculae on tergites, often absent on T4, especially among female; these maculae are well expressed and lunulate in E. longicornis in particular, but also in other species of the E. minotaurus group. Females of the E. minotaurus complex can be easily 
Table 5. Morphological differences between the E. minotaurus complex and E. longicornis.

\section{E. longicornis Loew, 1855}

Eyes almost bare

Ventral margin of basoflagellomere linear

Ventral pile of pedicel shorter than the depth of pedicel

Ventral pile of scape distinctly longer than ventral pile of pedicel

Ventral pile on femur short as the dorsal

Pollinose maculae on tergites II-IV wide, well expressed, third pair clearly oblique

distinguished from E. crassus females by the welldeveloped and wider pairs of maculae on T2-4 and the conspicuously developed pollinosity behind the posterior ocellus of E. crassus. Table 5 describes the clear morphological differences between the $E$. minotaurus complex and E. longicornis. The male genitalia of these two taxa are shown in Figure 10.

Distribution. Eastern Mediterranean (Greece, Montenegro).

General description. Male. Head. Eyes holoptic. Eye contiguity about 6 ommatidia long. Eye with scattered long white pilosity, bare near the margins. Face, vertex and occiput black to bronze, moderately punctuated. Face with uneven white to bronze pollinosity, less or more expressed but usually with a prominent longitudinal median stripe of silver pollinosity. Ocellar triangle isosceles, longer than wide (Figure $11 G)$. Face slightly convex, covered with white pile (Figure 11A). Pile on vertex and occiput yellow, but in ocellar triangle mixed with black. Scape and pedicel dark brown and covered with yellow pile, ventrally as long as the depth of the pedicel. Pedicel elongated, almost as long as the basoflagellomere (Figure 11AC). Basoflagellomere elongated, brown, from almost yellow to dark brown, covered with grey pollinosity. Sensory pit located ventrally near the distal margin of the basoflagellomere. Arista reddish-brown.

Thorax. Scutum, scutellum and pleurae black to bronze, moderately punctuated. Mesonotum anteriorly with fine white pollinosity that extends in two pollinose vittae, reaching $2 / 3$ of the length of the scutum. Median vitta present only in anterior part. Pile on thorax yellow to white, short on scutum and scutellum and longer on pleurae. Pleurae black with bronze to golden sheen, covered in silvery-white pollinosity and long white pile. Scutellum roughly

\section{E. minotaurus complex}

Eyes covered with moderately long and dense pile

Ventral margin of basoflagellomere slightly convex

Ventral pile of pedicel longer than the depth of pedicel

Ventral pile of scape about the same length as ventral pile of pedicel

Ventral pile on femur longer than the dorsal

Pollinose maculae on tergites II-IV narrow, linear, third pair often absent

transversely striated. Legs black to brown with reddish connections between segments, covered with golden pollinosity and moderately long white pile (Figure 11I). Metatrochanter covered in medium length pile. Metafemur moderately swollen, ventral pile yellow to white, as long as about half the depth of the femur. Metatibia greatly thickened, a little narrower than metafemur, slightly curved. Tarsi covered with short, dense, golden pile ventrally. Plumula covered in dark yellow pilosity. Wing with brown tinge. Costal bristles black.

Abdomen. Length: width of abdomen is about 1.4-1.6. Tergites black, densely punctuated, covered in short white pilosity that turns yellow in proximal half of T4. T1 with scarce white pollinosity laterally. T2-3 with pairs of silvery-white maculae of pollinosity, narrow, almost straight. Maculae on T4 barely visible, sometimes absent. Sternites light brown, covered with bronze pollinosity and moderately long white to yellow pile. S3 wide, on posterior margin with longer yellow to golden pile. Pregenital segment covered with golden pilosity.

Male genitalia. Posterior surstyle lobe large, covered with long scattered pile (Figure 10A, D). IL covered with short dense pilosity (Figure 10D). Hypandrium simple (Figure 10L). Distal part of aedeagal apodeme with processes that differ in shape in different species of the E. minotaurus complex (Figure 10G-I).

Female. Similar to the male with normal sexual dimorphism (Figure 11B, H, J). Frons less or more wrinkled longitudinally, in narrower part approximately as wide as one fourth of the width of the head in dorsal view or twice as wide as the width of the ocellar triangle. White pollinosity along eye margin less or more expressed. Pollinose maculae on T4 usually absent. 
We have resolved three cryptic species within the $E$. minotaurus complex: E. karyates sp. n., E. minotaurus and E.phaeacus sp. n.

Eumerus minotaurus Claussen and Lucas, 1988

Material studied. Paratypes. One male, Greece: Crete, one male, Lasithi, Sissi, 08.iv.1983, leg. Claussen; Heraclion, 7.iv.1975, leg. Lucas, (NBC). Additional material. Greece: one female, Crete, Rethimnon, Bali, 06.v.2003, leg. Tkalcu; one female, Orne-Agia Galini, 25.iv.2014, leg. Vujić; 2 males, Fotinos, 26.v.2014, leg. Vujić; Chania, one male, Armeni, 25.iv.2014, leg. Vujić; one female, Imbors, 27.v.2014, leg. Vujić; one male, one female, Omalos plain, 28.v.2014, leg. Vujić; Karpathos, one male, Avlona, 02-04.v.2012, leg. Vavitsas.

Diagnosis. Differs from other species of the $E$. minotaurus complex by the shape of the distal part of the aedeagal apodeme (Figure 10G), wing morphometric characters (significant wing shape differences), and molecular data (see accession numbers in Appendix). Basoflagellomere is usually pointed (Figure 11A).

Distribution. Greece: Crete and Karpathos.

Description. Size: body length $10-11.5 \mathrm{~mm}$; wing length 7-9 $\mathrm{mm}$.

Male. Width of face: width of head is $0.25-0.3$. Width of vertex: width of the head is 0.21-0.22. Length of eye contiguity: length of frons is 0.47 0.62. Basoflagellomere usually conspicuously pointed (Figure 11A). Width of pedicel: width of basoflagellomere is about 0.8 . Width of pedicel: length of pedicel is about 0.6. Thorax. Length: width of scutellum is 0.5 .

Female. Width of frons: width of head is 0.24-0.27. Width of pedicel: width of basoflagellomere is about 0.94 . Width of pedicel: length of pedicel is 0.5-0.8 Abdomen. Height: width ratio of T4 is 0.8. Height: width of T3 is $0.46-0.49$.

Eumerus karyates Chroni, Grković and Vujić sp. n.

Type material. Holotype. Male. Greece: Peloponnese, Karyes, 20.v.2016, legs. Vujić, Nedeljković, Ačanski, Likov, Miličić. Paratypes. Greece: Peloponnese, Karyes, three females, 20.v.2016; one male, 22.v.2016; two males, two females, 23.v.2016, legs. Vujić, Nedeljković, Ačanski, Likov, Miličić.

Diagnosis. Differs from other species of the $E$. minotaurus complex by the shape of the distal part of the aedeagal apodeme (Figure 10H), wing morphometric characters (significant wing shape differences) and molecular data (see accession numbers in Appendix). Basoflagellomere is slightly pointed, but less pronounced than in E. minotaurus (Figure 11C).

Distribution. Greece: Peloponnese.

Description. Size: body length $10-11 \mathrm{~mm}$; wing length 7-8 mm.

Male. Head. Width of face: width of head is 0.27 0.32 . Width of vertex: width of the head is $0.19-0.21$. Length of eye contiguity: length of frons is 0.29-0.42. Basoflagellomere usually slightly pointed (Figure 11C). Width of pedicel: width of basoflagellomere is $0.8-0.9$. Width of pedicel: length of pedicel is about 0.7. Thorax. Length: width of scutellum is 0.6.

Female. Head. Width of frons: width of head is 0.240.27 . Width of pedicel: width of basoflagellomere is $0.8-1$. Width of pedicel: length of pedicel is about 0.7 . Abdomen. Height: width of T4 is 0.7. Height: width of T3 is 0.46 .

Etymology. Karyatides are mainly known as the model figures sculptured as columns of the Erechtheion on the Acropolis of Athens and were the priestesses of Artemis at Karyae (today's Karyes) in ancient Laconia, Peloponnese. As all our Peloponnesian specimens derived from Karyes, we considered the male adjective "karyates" to be an appropriate name for the species.

Eumerus phaeacus Chroni, Grković and Vujić sp. n.

Type material. Holotype. Male. Greece: Corfu, Ano Korakiana, 24.v.2016, leg. Vujić, Nedeljković, Ačanski, Likov, Miličić. Paratypes. Montenegro, Rumija, one male, 42.11201 Lat., 111.217311 Long., 02.v.2011, leg. Vujić; Greece: Mt Olympus, one male, one female, Ag. Paraskevi, 17.v.2011, leg. Vujić; Corfu, Ano Korakiana, 14 males, 24.v.2016, leg. Vujić, Nedeljković, Ačanski, Likov, Miličić; four males, one female, Liapades, 24.v.2016, leg. Vujić, Nedeljković, Ačanski, Likov, Miličić; one male, Strinilas, 24.v.2016, leg. Vujić, Nedeljković, Ačanski, Likov, Miličić.

Diagnosis. Differs from other species of the $E$. minotaurus complex by the shape of the distal part of the aedeagal apodeme (Figure 10I), the absence of pollinosity behind the posterior ocelli, wing morphometric characters (significant wing shape differences) and molecular data (see accession numbers in Appendix). Basoflagellomere is rounded, which is quite a stable character in this species (Figure 11B). Distribution. Montenegro: Mt Rumija, Greece: Corfu, Mt Olympus. 
Description. Size: body length $10-11 \mathrm{~mm}$; wing length 7-8 mm.

Male. Width of face: width of head is $0.28-0.32$. Width of vertex: width of the head is $0.19-0.23$. Length of eye contiguity: length of frons is $0.28-0.4$. Basoflagellomere almost always rounded (Figure 11B). Width of pedicel: width of basoflagellomere is about 0.8 . Width of pedicel: length of pedicel is about 0.8. Thorax. Length: width of scutellum is 0.5-0.6.

Female. Width of frons: width of head is 0.27 . Width of pedicel: width of basoflagellomere is 0.8 . Width of pedicel: length of pedicel is 0.6. Abdomen. Height: width of T4 is 0.7. Height: width of T3 is 0.45 .

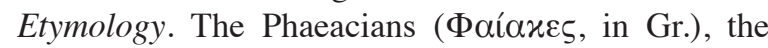
ancient inhabitants of Corfu Island, were famous for their nautical skills, and renowned for their ability to travel and rapidly reach any location. We selected this name given the origin of the majority of our insect specimens (Corfu) and the wide geographic range of the species.

\section{Taxonomic notes}

Doczkal (1996) noted the morphological affinity between E. minotaurus and E. longicornis and their dissimilarity to $E$. niehuisi, with the latter being morphologically similar and closely related to $E$. crassus. The first two species can be distinguished from the latter two by their slightly shorter body pile, the pruinose supra-alar area without transverse striae, and the scutum without black pile. The pedicels of $E$. crassus and E. niehuisi are about 1.5 times as long as deep (Figure 11E), whereas in E. longicornis (Figure $11 \mathrm{~F}$ ) and the E. minotaurus complex (Figure 11A-C) the pedicel is about twice as long as deep.

\section{New species for the Eumerus minotaurus group}

Eumerus anatolicus Grković, Vujić and Radenković sp. n.

Type material. Holotype. Male. Turkey: Muğla, University campus (720 m), iv.2011. leg. Kavak. Paratypes. Muğla, University campus $(720 \mathrm{~m})$, one female, 17-22.v.2011. legs. Barták and Kubík, 3 males, iv.2011, 2 males, 26.v.-26.vi.2015 leg. Kavak.

Diagnosis. Species belongs to the E. minotaurus group and presents the highest similarity to the $E$. minotaurus complex compared to other species of the E. minotaurus group, but also displays clear differences to the E. minotaurus complex.
E. anatolicus sp. n. can be distinguished from $E$. crassus and E. longicornis by the longer pile on the ventral metatrochanter and metafemur, as well as by the shape of the basoflagellomere (Figure 11D) and the posterior lobe of the surstylus (Figure 10C). $E$. anatolicus sp. n. can be distinguished from the three cryptic species belonging to the E. minotaurus complex by patches of grey to white pollinosity on the vertical triangle anteriorly and near the posterior ocelli, as well as by distinctive pollinose maculae on T2-4. In the E. minotaurus complex, these markings are linear on T3, whereas in E. anatolicus sp. n. they are wider and lunulate. This character is also present in females. Additionally, the vertex of the new species is moderately punctuated and shiny, whereas in the E. minotaurus complex it is roughly punctuated and matte. Also, in females of the E. minotaurus complex, the frons is wrinkled and covered in white pollinosity along the eye margin apart from an interruption in front of the ocellar triangle, whereas in E. anatolicus sp. n., frons is shinier and with a continuous line of pollinosity along the eye margin, as far as the wide pollinose patch behind the posterior ocelli. Regarding the male genitalia, they are very similar to those in the E. minotaurus complex but with a slightly larger posterior surstyle lobe and with denser pilosity (Figure 10C) that extends along almost the entire length of the ventral margin (Figure 10F); in species of the E. minotaurus complex, this pilosity is restricted to the upper part of the posterior surstyle lobe and sometimes with only a few pile lower down (Figure 10D). The inner lobe of the anterior surstylus is more oval in lateral view than in the E. minotaurus complex, covered with fine short pilosity (Figure 10C). The apical part of the aedeagal apodeme is clearly different from those in the E. minotaurus complex (Figure 10J).

Distribution. Turkey: Muğla.

Description. Size: body length 10-12 mm; wing length 7-10.5 mm.

Male. Head. Width of face: width of head is $0.30-0.33$. Width of vertex: width of head is $0.22-0.24$. Length of eye contiguity: length of frons is $0.40-0.47$. Eye contiguity 6-10 ommatidia long. Eyes covered in long dense white pilosity, bare near posterior margins. Face, frons, vertex and occiput black with bronze sheen. Face and frons covered in very dense silverywhite pollinosity and white pile. Frons laterally often with a few long black pile mixed with black. Face convex. Vertex and occiput moderately punctuated. Pile on vertex and occiput yellow mixed with black. 
Ocelli arranged in an isosceles triangle, longer than wide. Scape and pedicel brown, covered in dense yellow pile, ventrally sometimes longer than the depth of the pedicel. Pedicel elongated, approximately as long as the basoflagellomere and even longer in some specimens (Figure 11D). Width of pedicel: width of basoflagellomere is about 0.9 . Width of pedicel: length of pedicel is about 0.7. Basoflagellomere is usually pointed but in some specimens it is oval with the ventral margin quite convex. Thorax. Scutum, scutellum and pleurae black to bronze, densely punctuated. Pleurae, anterior scutum and supra-alar area with fine white pollinosity. Mesonotum with two longitudinal vittae of pollinosity extending up to $4 / 5$ of the length. Narrow median vitta present, almost as long as lateral vittae. Pile on thorax white to yellow. Scutellum roughly striated transversely. Length: width of scutellum is 0.5 0.6. Legs black, tips of femora at both sides brownish. Base of tibiae brownish. Metafemur slightly swollen, ventral pile approximately as long as half the depth of the femur. Metatibia curved in the middle. Wings with dark tinge, entirely microtrichose. Abdomen. Tergites black, densely punctuated and covered in short white pilosity that turns yellow to golden in the posterior half of T4. T2-4 with clearly visible, wide, lunulate maculae of pollinosity. Maculae on T4 narrower. Sternites brown with long white to yellow pile. S4 broad, with yellowish pile posterolaterally. Genitalia. Posterior surstyle lobe large, covered in long, dense and evenly distributed pilosity (Figure 10C). IL covered with short dense pile. Ventral margin of surstylus densely pilose, almost along entire length (Figure 10F).

Female. Similar to the male with normal sexual dimorphism. Head. Width of frons: width of head is 0.3 . Frons shiny, moderately punctuated with a continuous line of pollinosity along the eye margin as far as the wide pollinose patch behind the posterior ocelli. 